\title{
Baseline Skills Assessment of the US Army Research Laboratory
}

\author{
by Josephine Q Wojciechowski
}

ARL-TR-7181

January 2015 


\section{NOTICES}

\section{Disclaimers}

The findings in this report are not to be construed as an official Department of the Army position unless so designated by other authorized documents.

Citation of manufacturer's or trade names does not constitute an official endorsement or approval of the use thereof.

Destroy this report when it is no longer needed. Do not return it to the originator. 


\section{Army Research Laboratory}

Aberdeen Proving Ground, MD 21005-5425

\section{Baseline Skills Assessment of the US Army Research Laboratory}

Josephine Q Wojciechowski

Office of the Director, ARL 


\section{REPORT DOCUMENTATION PAGE}

Form Approved OMB No. $0704-0188$

Public reporting burden for this collection of information is estimated to average 1 hour per response, including the time for reviewing instructions, searching existing data sources, gathering and maintaining the data needed, and completing and reviewing the collection information. Send comments regarding this burden estimate or any other aspect of this collection of information, including suggestions for reducing the burden, to Department of Defense, Washington Headquarters Services, Directorate for Information Operations and Reports (0704-0188), 1215 Jefferson Davis Highway, Suite 1204, Arlington, VA 22202-4302. Respondents should be aware that notwithstanding any other provision of law, no person shall be subject to any penalty for failing to comply with a collection of information if it does not display a currently valid OMB control number.

PLEASE DO NOT RETURN YOUR FORM TO THE ABOVE ADDRESS.

\begin{tabular}{|c|c|c|}
\hline $\begin{array}{l}\text { 1. REPORT DATE (DD-MM-YYYY) } \\
\text { January } 2015\end{array}$ & $\begin{array}{l}\text { 2. REPORT TYPE } \\
\text { Final }\end{array}$ & $\begin{array}{l}\text { 3. DATES COVERED (From - To) } \\
1-31 \text { July } 2014\end{array}$ \\
\hline \multirow{4}{*}{\multicolumn{2}{|c|}{$\begin{array}{l}\text { 4. TITLE AND SUBTITLE } \\
\text { Baseline Skills Assessment of the US Army Research Laboratory }\end{array}$}} & 5a. CONTRACT NUMBER \\
\hline & & \\
\hline & & 5b. GRANT NUMBER \\
\hline & & 5c. PROGRAM ELEMENT NUMBER \\
\hline \multirow{3}{*}{\multicolumn{2}{|c|}{$\begin{array}{l}\text { 6. AUTHOR(S) } \\
\text { Josephine Q Wojciechowski }\end{array}$}} & 5d. PROJECT NUMBER \\
\hline & & 5e. TASK NUMBER \\
\hline & & 5f. WORK UNIT NUMBER \\
\hline \multicolumn{2}{|c|}{$\begin{array}{l}\text { 7. PERFORMING ORGANIZATION NAME(S) AND ADDRESS(ES) } \\
\text { US Army Research Laboratory } \\
\text { ATTN: RDRL-D } \\
\text { Aberdeen Proving Ground, MD } 21005\end{array}$} & $\begin{array}{l}\text { 8. PERFORMING ORGANIZATION } \\
\text { REPORT NUMBER } \\
\text { ARL-TR-7181 }\end{array}$ \\
\hline \multirow{2}{*}{\multicolumn{2}{|c|}{ 9. SPONSORING/MONITORING AGENCY NAME(S) AND ADDRESS(ES) }} & 10. SPONSOR/MONITOR'S ACRONYM(S) \\
\hline & & $\begin{array}{l}\text { 11. SPONSOR/MONITOR'S REPORT } \\
\text { NUMBER(S) }\end{array}$ \\
\hline
\end{tabular}

12. DISTRIBUTIONIAVAILABILITY STATEMENT

Approved for public release; distribution is unlimited.

13. SUPPLEMENTARY NOTES

\section{ABSTRACT}

The US Army Research Laboratory (ARL) started several corporate initiatives to benchmark and improve upon strategic areas of the laboratory. These initiatives, designed to investigate a critical interest area, each began with a study led by a senior leader. The intent was to propose recommendations and an implementation plan for the next several years. One of these initiatives, Skills Assessment, was designed to examine the current state of the human capital of the organization. Dr Laurel Allender, director of the Human Research and Engineering Directorate, was tasked to lead a team of representatives from each of the other directorates in ARL and appropriate support functions in assessing the human capital of ARL. At the same time, ARL began a process to realign the long-term direct mission program to a set of science and technology campaigns. The ARL campaign plans would be collaborative and crosscutting focus areas for the mission program. The team used the campaign taxonomy to define the competencies for ARL and collected data for each ARL scientist or engineer, including all post docs and contractors based on the competency lists. A gap analysis was then completed. There were areas where ARL has little competency but planned to lead or collaborate in that area as well as areas where we had large numbers of people claiming competency yet we did not plan future efforts. Although the data were not exact, the study provides a place to begin to benchmark the ARL skill mix.

15. SUBJECT TERMS

skills, competency, campaign plans, baseline, assessment

\begin{tabular}{|l|l|l|l|c|l|}
\hline \multicolumn{2}{|l|}{ 16. SECURITY CLASSIFICATION OF: } & $\begin{array}{l}\text { 17. LIMITATION } \\
\text { OF ABSTRACT }\end{array}$ & $\begin{array}{l}\text { 18. NUMBER } \\
\text { OF PAGES }\end{array}$ & $\begin{array}{l}\text { 19a. NAME OF RESPONSIBLE PERSON } \\
\text { Josephine Q Wojciechowski }\end{array}$ \\
\cline { 1 - 2 } $\begin{array}{l}\text { a. REPORT } \\
\text { Unclassified }\end{array}$ & $\begin{array}{l}\text { b. ABSTRACT } \\
\text { Unclassified }\end{array}$ & $\begin{array}{l}\text { c. THIS PAGE } \\
\text { Unclassified }\end{array}$ & UU & 84 & $\begin{array}{l}\text { 19b. TELEPHONE NUMBER (Include area code) } \\
(410) 278-5938\end{array}$ \\
\hline
\end{tabular}




\section{Contents}

List of Figures $\quad$ v

List of Tables $\quad$ vii

$\begin{array}{ll}\text { Acknowledgments } & \text { ix }\end{array}$

$\begin{array}{ll}\text { 1. Introduction } & 1\end{array}$

2. Background 2

$\begin{array}{lr}\text { 3. } & \text { Method }\end{array}$

4. Results $\quad 5$

$\begin{array}{lr}\text { 5. Discussion } & 8\end{array}$

6. Conclusions and Recommendations $\quad 10$

7. References $\quad 12$

$\begin{array}{ll}\text { Appendix A. Campaign Competency Selections } & 13\end{array}$

Appendix B. Extramural Basic Research Campaign Data $\quad 21$

Appendix C. Human Sciences Campaign Data 25

Appendix D. Information Sciences Campaign Data $\quad 31$

Appendix E. Sciences for Lethality and Protection Campaign Data 37

Appendix F. Sciences for Maneuver Campaign Data 45

Appendix G. Materials Research Campaign Data 49

$\begin{array}{ll}\text { Appendix H. Computational Sciences Campaign Data } & 61\end{array}$ 


\section{List of Figures}

Fig. 1 ARL campaign plans

Fig. 2 Mapping from the competency list used to collect data to the level 3 categories for the Sciences for Lethality and Protection Campaign.

Fig. 3 Instances chosen for Extramural Basic Research Campaign competencies ......................6

Fig. B-1 Instances chosen for Extramural Basic Research Campaign competencies.................22

Fig. B-2 Instances chosen for Extramural Basic Research Campaign competencies for proficiency level 3 only

Fig. C-1 Instances chosen for Human Sciences Campaign Competencies.

Fig. C-2 Instances chosen for Human Sciences Campaign Competencies for proficiency level 3 only.

Fig. D-1 Instances chosen for Information Sciences Campaign competencies

Fig. D-2 Instances chosen for Information Sciences Campaign competencies for proficiency level 3 only.

Fig. E-1 Instances chosen for Sciences for Lethality and Protection Campaign competencies as defined by campaign level 3 taxonomy....

Fig. E-2 Instances chosen for Sciences for Lethality and Protection Campaign Competencies from list provided

Fig. E-3 Instances chosen for Sciences for Lethality and Protection Campaign for proficiency level 3 only (campaign level 3 taxonomy)

Fig. E-4 Instances chosen for Sciences for Lethality and Protection Campaign competencies for proficiency level 3 only (competency list created for data collection)

Fig. E-5 Personnel choosing Sciences for Lethality and Protection Campaign competencies for proficiency level 3 only (competency list created for data collection)

Fig. F-1 Instances chosen for Sciences for Maneuver Campaign competencies.....

Fig. F-2 Instances chosen for Sciences for Maneuver Campaign competencies for proficiency level 3 only

Fig. G-1 Instances chosen for Materials Research Campaign competencies for areas ARL will lead.....

Fig. G-2 Instances chosen for Materials Research Campaign competencies in areas where ARL will collaborate and follow

Fig. G-3 Instances chosen for Materials Research Campaign competencies for proficiency level 3 only in areas where ARL will lead.

Fig. G-4 Instances chosen for Materials Research Campaign competencies for proficiency level 3 only in areas where ARL will collaboration and follow... 
Fig. H-1 Instances chosen for Computational Sciences Campaign competencies

Fig. H-2 Instances chosen for Computational Sciences Campaign competencies for

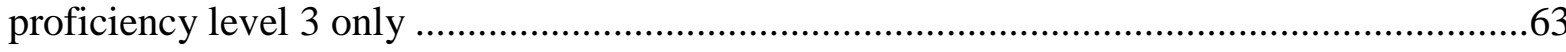

Fig. I-1 Instances chosen for Assessment and Analysis Campaign competencies .....................66

Fig. I-2 Instances chosen for Assessment and Analysis Campaign competencies for proficiency level 3 only ...........................................................................................6 


\section{List of Tables}

Table 1 Skill assessment corporate initiative team members ................................................

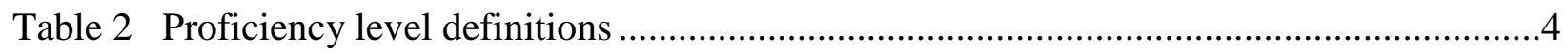

Table 3 Number of instances of competencies by campaign for each directorate.......................6

Table 4 Personnel choosing Extramural Basic Research Campaign competencies ....................7

Table 5 Write-in competencies assigned to Extramural Basic Research Campaign ....................7

Table B-1 Personnel choosing Extramural Basic Research Campaign competencies ...............23

Table B-2 Write-in competencies assigned to Extramural Basic Research Campaign ...............23

Table B-3 Personnel choosing Extramural Basic Research Campaign competencies for

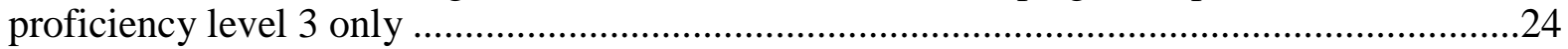

Table C-1 Personnel choosing Human Sciences Campaign competencies .............................27

Table C-2 Write-in competencies assigned to Human Sciences Campaign ..............................28

Table C-3 Personnel choosing Human Sciences Campaign competencies for proficiency

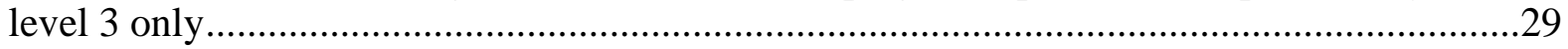

Table D-1 Personnel choosing Information Sciences Campaign competencies.........................33

Table D-2 Write-in competencies assigned to the Informational Sciences Campaign................34

Table D-3 Personnel choosing Information Sciences Campaign competencies for

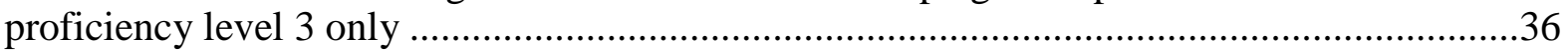

Table E-1 Personnel choosing Sciences for Lethality and Protection Campaign competencies as defined by level 3 taxonomy.

Table E-2 Personnel choosing Sciences for Lethality and Protection Campaign competencies from list provided.

Table E-3 Write-in competencies assigned to Sciences for Lethality and Protection Campaign .....

Table E-4 Personnel choosing Sciences for Lethality and Protection Campaign competencies for proficiency level 3 only (campaign level 3 taxonomy) ............................41

Table F-1 Personnel choosing Sciences for Maneuver Campaign competencies.......................46

Table F-2 Personnel choosing Sciences for Maneuver Campaign competencies for proficiency level 3 only

Table G-1 Personnel choosing Materials Research Campaign competencies for areas ARL will lead......

Table G-2 Personnel choosing Materials Research Campaign competencies in areas where

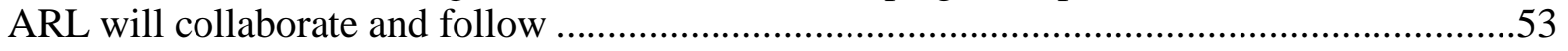

Table G-3 Write-in competencies assigned to the Materials Research Campaign . .54 
Table G-4 Personnel choosing Materials Research Campaign competencies for proficiency

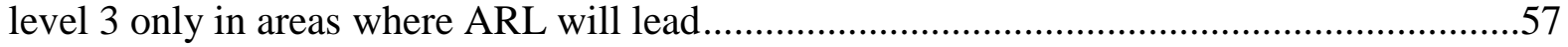

Table G-5 Personnel choosing Materials Research Campaign competencies for proficiency level 3 only in areas where ARL will collaborate and follow .........................................59

Table H-1 Personnel choosing Computational Sciences Campaign competencies ....................62

Table H-2 Write-in competencies assigned to Computational Sciences Campaign...................63

Table H-3 Personnel choosing Computational Sciences Campaign competencies for

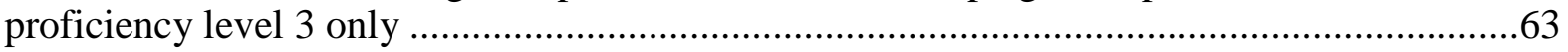

Table I-1 Personnel choosing Assessment and Analysis Campaign competencies...................67

Table I-2 Write-in competencies for Assessment and Analysis Campaign..............................67

Table I-3 Personnel choosing Assessment and Analysis Campaign competencies for

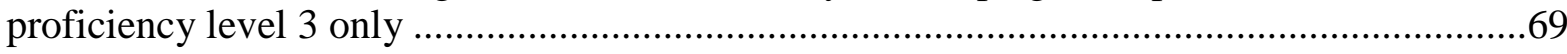




\section{Acknowledgments}

The author would like to acknowledge the entire Skills Assessment Team. They did the difficult task of determining how "skills" would be defined. The team researched assessment tools and actions to see if and how each one might best be applied to the laboratory. When an acceptable one could not be identified, the team used the new campaign plan taxonomy to develop competency lists. This could not have been done without the support and hard work of everyone on the team. Once the competency lists were complete, it was just number crunching.

Additionally, this effort would not have come together without the guidance from Dr Laurel Allender, and Mr John F Lockett, when she was detailed to another position. Their guidance and direction were paramount to the success of this assessment. 
INTENTIONALLY LEFT BLANK. 


\section{Introduction}

In the fall of 2013, the US Army Research Laboratory (ARL) began several corporate initiatives to benchmark and improve upon the most strategic areas of the laboratory. These initiatives were to begin with a study led by a senior leader and designed to investigate a critical interest area. The outcome of the study would be a recommendation plan to be implemented over the next several years.

One of these initiatives, titled "Skills Assessment", was designed to examine the current state of the human capital of the organization. Dr Laurel Allender, director of ARL's Human Research and Engineering Directorate (HRED), was tasked to lead a team of representatives from each of the other directorates and appropriate support functions in ARL to assess the human capital of ARL. Team members are listed in Table 1.

Table 1 Skill assessment corporate initiative team members

\begin{tabular}{|l|l|}
\hline \multicolumn{1}{|c|}{ Organization } & \multicolumn{1}{c|}{ Name } \\
\hline \multirow{2}{*}{ Director lead } & Dr Laurel Allender/Mr John Lockett \\
\hline \multirow{3}{*}{ Office of the Director support } & Ms Sue Hickman \\
\cline { 2 - 2 } & Ms Diane Hawkins \\
\cline { 2 - 2 } Human Research and Engineering Directorate representative & Dr Val Emery \\
\cline { 2 - 2 } & Ms Jackie Laroche \\
\cline { 2 - 2 } Army Research Office representative & Ms Natalie Simon \\
\hline Computational and Information Sciences Directorate representative & Dr Tom Doligalski \\
\hline Sensors and Electron Devices Directorate representative & Dr Don Headley \\
\cline { 2 - 2 } Survivability/Lethality Analysis Directorate representative & Dr Tom Davis \\
\cline { 2 - 2 } & Ms Jody Wojciechowski \\
\hline \multirow{2}{*}{ Vehicle Technology Directorate representative } & Dr Nasser Nasrabadi \\
\hline Weapons and Materials Research Directorate representative & Mr John Beilfuss \\
\hline
\end{tabular}

At the same time, ARL began a process to realign the long-term direct mission program to a set of science and technology (S\&T) "campaigns". The ARL campaign plans would be collaborative and crosscutting focus areas for the mission program. The 8 campaigns, shown in Fig.1, are as follows:

- Extramural Basic Research

- Human Sciences

- Information Sciences 
- Sciences for Lethality and Protection

- Sciences for Maneuver

- Materials Research

- Computational Sciences

- Assessment and Analysis

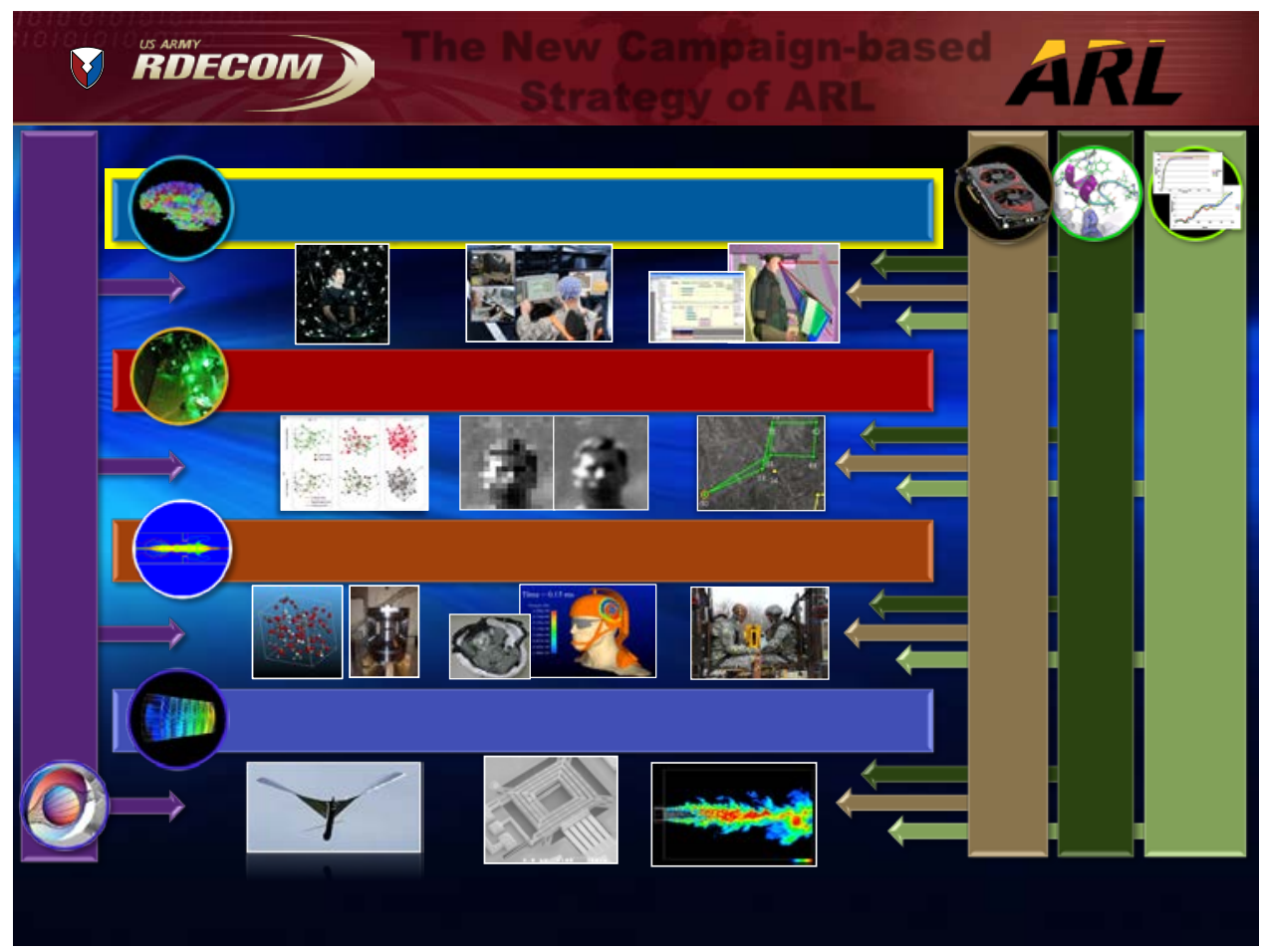

Fig. 1 ARL campaign plans

To relate the current skill set to the future needs of the ARL, the campaign plans were referenced as the future mission program. This report summarizes the results and recommendations of the skills assessment corporate initiative study.

\section{Background}

The first step in completing a skill assessment was to define skill. Many different sources were researched to determine how to define skill. The US Office of Personnel Management (2014) defines knowledge, skills, and abilities (KSAs), or competencies, as

the attributes required to perform a job and are generally demonstrated through qualifying experience, education and training. Knowledge is a body of information applied directly to the performance of a function. Skill is an observable competence 
to perform a learned psychomotor act. Ability is the competence to perform an observable behavior or a behavior that results in an observable product.

It was this definition of competency or KSAs that we were hoping to capture in our analysis.

A decision was made early on to focus on the scientists and engineers (S\&Es) in the laboratory. There were Army-level and Department of Defense-level efforts underway to look at competencies in different areas of the workforce. These efforts initially began with a focus on human resource personnel. Additionally, there was discussion about measuring skills in terms of leadership. As this presented a different level of effort, it was decided to focus on the S\&E workforce for the initial study.

Personnel records were examined for data already on hand that could be used to evaluate competencies. Education is captured in the degrees achieved by ARL employees. Just having a degree does not, however, capture any qualifying experience. We considered using position descriptions but these do not capture the specific area that individuals work. Additionally, each employee is assigned a specialty work code (SWC). These are meant to better describe the work that the employee is doing. However, SWCs varied greatly from directorate to directorate. One directorate had 63 SWCs while another had basically 1 . These did not capture competency either. About this time, the US Army Research, Development and Engineering Command (RDECOM) published a survey of all its staff and subordinates to understand competencies and potential areas of overlap between the RDECOM components. This survey was very thorough, but because they were looking across the entire command, the level of competency breakdown was not sufficient for our purposes.

The search for a competency list brought us to the campaign plans and its taxonomic breakdowns. Because the campaign plans' level 3 taxonomy seemed to describe the competencies of the laboratory, it was decided that we would use the level 3 taxonomy where we could. For the Sciences for Lethality and Protection (SLaP) Campaign, the level 3 taxonomy was not as detailed a taxonomy than the other campaigns. A more detailed list of competencies was generated by the representative from the Weapons and Materials Research Directorate (WMRD). The list was vetted by representatives from the directorate and used to collect competency data.

The level of expertise ARL might have in each of the competency areas was also important to this assessment. One might have a competency area where he/she is an expert while another person might just be out of college without much experience. It was decided that for each competency reported, one should indicate the individual's proficiency in that area. A 3-level proficiency breakdown was used in this assessment. The proficiency levels are described in Table 2. 
Table 2 Proficiency level definitions

\begin{tabular}{|c|l|}
\hline Level & \multicolumn{1}{c|}{ Definition } \\
\hline 1 & Basic understanding, minimal experience \\
\hline 2 & More specific understanding, some level of application \\
\hline 3 & Expertise, experienced in the field \\
\hline
\end{tabular}

\section{Method}

Once the decision was made to collect competencies by campaign plans, we created an Excel spreadsheet to collect skill competency and proficiency data for each scientist and engineer in ARL. The spreadsheet contained information for each S\&E civilian that described one's position and location in ARL. The list was sorted by branch, and branch chiefs were asked to identify the appropriate competency(s) for their employees and the proficiency level of those competencies. They were allowed to identify up to 3 competencies for each employee from the complete list covering all campaigns and add a "write-in" competency if there was not one from the list that fit. They were then asked to add any contractors and/or post docs without attaching personal information to them to avoid contractual legal issues. Tables in Appendix A have the list of competencies by campaign. Once the data were collected, the results were summarized.

Several assumptions were made in collating the data. If proficiency level was not indicated by the branch chief, it was assumed to be level 3. This was done because in many of the instances where proficiency was left off, the competency listed was the only competency or a write-in competency. In these cases, one would assume that the individual would have expertise in this field.

We wanted to look at our competencies (areas) as a function of whether the ARL would lead, collaborate, or follow. Unfortunately, these designations on the campaign plans were made at level 4 of the taxonomy and we had collected competency data at level 3 . Where we could get agreement from the campaign plan representatives, we determined what the level 3 designation would be. Where we were unable to coordinate with the campaign representatives, we weighted the level 4 categories of lead, collaborate, or follow to determine the designation at level 3. For the SLaP Campaign, we had used a list provided by WMRD instead of the campaign level 3 taxonomy. We mapped that list to the SLaP Campaign level 3 taxonomy. That mapping is shown in Fig. 2. This mapping was completed to show how the competency list we used to collect data related to the actual SLaP Campaign level 3 taxonomy. Data are presented for both the competency list and the mapping to campaign taxonomy.

The write-in competencies allowed for each employee, whether government employee or post doc/contractor, were consolidated by campaign based on key words. 


\begin{tabular}{|c|c|}
\hline Sciences for Lethality and Protection & $\begin{array}{c}\text { Sciences for Lethality and } \\
\text { Protection }\end{array}$ \\
\hline Energetic Materials and Propulsion & \\
\hline Projectile Maneuverability & \\
\hline Projectile Navigation & Weapon/Energy Projection \\
\hline Sensors & \\
\hline Soft-Kill & \multirow{3}{*}{ Electronic Attack/Protect } \\
\hline Active Base Protection & \\
\hline Active Protection Systems & \\
\hline Armor & \multirow{2}{*}{ Weapon-Target Interaction } \\
\hline Counter Measures & \\
\hline Decoys and Obscurants & \\
\hline Fire Suppression/Protection & \multirow{2}{*}{ Prediction/Assessment Tools } \\
\hline Hit Avoidance Technologies & \\
\hline Kinetic Penetrators & \\
\hline Non-Lethal Technologies & \multirow{2}{*}{ Launch and Control } \\
\hline Novel Lethal Mechanisms & \\
\hline Passive Base Protection & \multirow[b]{2}{*}{ Human Response to Threats } \\
\hline Personal Protective Equipment & \\
\hline $\begin{array}{c}\text { Threat Avoidance } \\
\text { Warhead, Fuze, S\&A }\end{array}$ & \multirow{3}{*}{ Counter CBRNE Threats } \\
\hline Diagnostics and Instrumentation & \\
\hline Directed Energy Technologies & \\
\hline Guns-Launchers & \\
\hline Technical Fire Control & \\
\hline
\end{tabular}

Note: CBRNE = chemical, biological, radiological, nuclear, and explosives

Fig. 2 Mapping from the competency list used to collect data to the level 3 categories for the Sciences for Lethality and Protection Campaign

\section{Results}

Our data are summarized by directorate, campaign and proficiency level, and by civilian versus post doc versus contractor. Values provided in the tables and graphs represent the number of instances the competency was reported.

Table 3 shows the number of instances of competencies each directorate identified in each of the campaigns. These numbers are summarized at the campaign level 1. As an exemplar for one campaign, a breakdown of competencies within the Extramural Basic Research Campaign is shown in Fig. 3. Similarly, Table 4 shows the number of instances the Extramural Basic Research Campaign areas were chosen as a function of status of employee: civilian, post doc, or contractor. 
Table 3 Number of instances of competencies by campaign for each directorate

\begin{tabular}{|l|c|c|c|c|c|c|c|c|c|}
\hline \multicolumn{1}{|c|}{ Campaign } & ARO & CISD & HRED & SEDD & SLAD & VTD & WMRD & ODIR & LABOPS \\
\hline Number of personnel surveyed & 39 & 224 & 220 & 326 & 358 & 78 & 608 & 13 & 18 \\
\hline Extramural basic research & 48 & 16 & 4 & 36 & 4 & 0 & 50 & 5 & 9 \\
\hline Human sciences & 7 & 21 & 420 & 1 & 3 & 0 & 21 & 2 & 3 \\
\hline Information sciences & 1 & 182 & 7 & 145 & 1 & 0 & 4 & 1 & 0 \\
\hline Sciences for lethality and protection & 1 & 4 & 1 & 49 & 170 & 0 & 449 & 8 & 5 \\
\hline Sciences for maneuver & 0 & 54 & 18 & 26 & 7 & 132 & 39 & 0 & 23 \\
\hline Materials research & 14 & 25 & 5 & 374 & 32 & 39 & 443 & 5 & 2 \\
\hline Computational sciences & 1 & 246 & 14 & 3 & 40 & 0 & 63 & 1 & 0 \\
\hline Assessment and analysis & 2 & 36 & 85 & 6 & 595 & 14 & 22 & 8 & 0 \\
\hline
\end{tabular}

Notes: ARO = Army Research Office, CISD = Computational and Information Sciences Directorate, HRED = Human Research and Engineering Directorate, SEDD = Sensors and Electron Devices Directorate, SLAD = Survivability/Lethality Analysis

Directorate, VTD = Vehicle Technology Directorate, WMRD = Weapons and Materials Research Directorate, ODIR = Office of the Director, LABOPS = Laboratory Operations

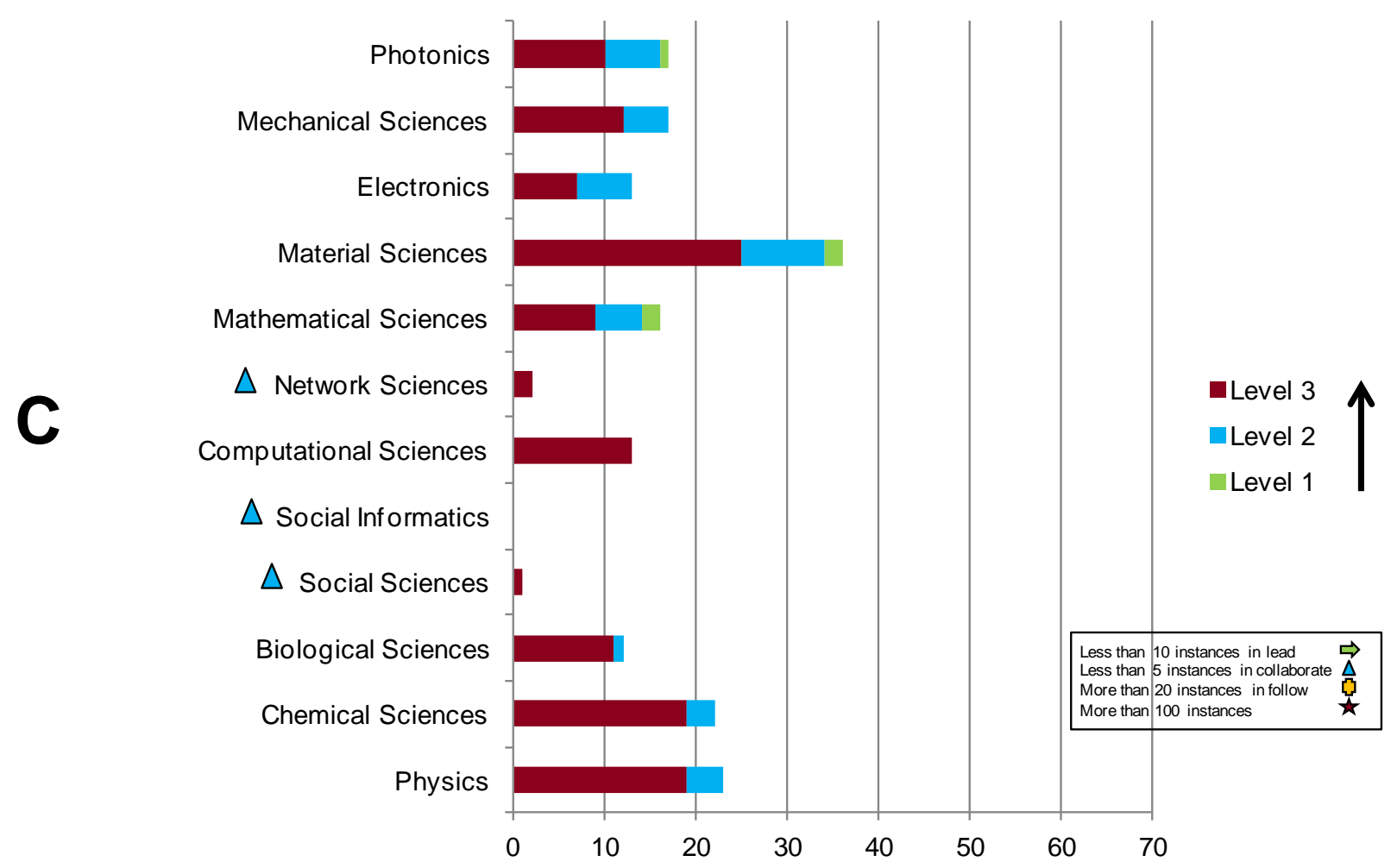

Fig. 3 Instances chosen for Extramural Basic Research Campaign competencies 
Table 4 Personnel choosing Extramural Basic Research Campaign competencies

\begin{tabular}{|l|c|c|c|c|}
\hline \multicolumn{1}{|c|}{ Extramural Basic Research } & Civilians & Post Docs & Contractors & Total \\
\hline Photonics & 16 & $\ldots$ & 1 & 17 \\
\hline Mechanical sciences & 15 & $\ldots$ & 2 & 17 \\
\hline Electronics & 13 & $\ldots$ & $\ldots$ & 13 \\
\hline Materials research & 34 & 1 & 1 & 36 \\
\hline Mathematical sciences & 15 & 1 & $\ldots$ & 16 \\
\hline$\wedge$ Network sciences & 2 & $\ldots$ & $\ldots$ & 2 \\
\hline Computational sciences & 9 & 2 & 2 & 13 \\
\hline$\wedge$ Social informatics & 0 & $\ldots$ & $\ldots$ & 0 \\
\hline$\wedge$ Social sciences & 0 & $\ldots$ & 1 & 1 \\
\hline Biological sciences & 11 & $\ldots$ & 1 & 12 \\
\hline Chemical sciences & 14 & 2 & 6 & 22 \\
\hline Physics & 21 & $\ldots$ & 2 & 23 \\
\hline
\end{tabular}

$\wedge$ Less than 5 instances in a collaborate area

Branch chiefs were given the option of providing one write-in competency if they felt that the list did not sufficiently describe the competencies of their employees. The write-in competencies were summarized by the campaign plan area where it was believed they belonged. The list for the Extramural Basic Research Campaign is shown in Table 5.

Table 5 Write-in competencies assigned to Extramural Basic Research Campaign

\begin{tabular}{|l|c|}
\hline \multicolumn{1}{|c|}{ Competency } & Total \\
\hline Fundamental research-laser induced breakdown spectroscopy & 1 \\
\hline Mechanical sciences & 1 \\
\hline Mechanics and materials & 1 \\
\hline Photonics & 4 \\
\hline Physics & 2 \\
\hline Statistical analysis & 1 \\
\hline Theoretical and numerical chemistry & 1 \\
\hline Quantum chemistry & 1 \\
\hline Optimization in chemical compound space & 35 \\
\hline Fundamental research-extramural basic research & 1 \\
\hline Condense matter physics & 2 \\
\hline Device physics & 1 \\
\hline Multidisciplinary organic synthetic chemical and biotechnology & 1 \\
\hline Multidisciplinary analytical chemistry electrochemistry and bio & 1 \\
\hline Multidisciplinary analytical chemistry/spectroscopy and biotechnology & 2 \\
\hline Multidisciplinary physics and biotechnology & 1 \\
\hline Photonics and lasers & 1 \\
\hline Quantum sciences-basic physics & \\
\hline
\end{tabular}


Data for all campaigns are provided in Appendixes B-I by campaign. In the figures, each colored bar indicates level of proficiency (level 3 is the highest). The areas that ARL will lead are identified by the " $\mathrm{L}$ " to the left of the $\mathrm{y}$-axis labels. The areas in which ARL will collaborate are identified by the " $C$ " to the left of the $y$-axis labels and separated from the "Lead" area by a horizontal line. The campaign areas in which ARL will watch or follow are identified by "F" to the left of the $y$-axis label and separated from the collaborate area by a horizontal line. Items of interest are highlighted in each of these figures using symbols. When a campaign area that was considered a lead area had less than 10 instances identified, it was indicated with a green arrow. When a campaign area that was considered a collaborate area had less than 5 instances identified, it was indicated with a blue triangle. Similarly, areas we follow that have 20 or more instances identified were indicated with a yellow cross. Lastly, maroon stars indicated any area that had more than 100 instances identified. These markers are shown in the figure keys.

For the tables in the appendixes, the areas that ARL will lead are highlighted in green. The areas in which ARL will collaborate are highlighted in blue. The campaign areas in which ARL will watch or follow are highlighted in peach. Areas of interest are also indicated in these tables with symbols. When a campaign area that was considered a lead area had less than 10 instances identified, it was indicated with a greater-than symbol. When a campaign area that was considered a collaborate area had less than 5 instances identified, it was indicated with a carat symbol. Similarly, areas we follow that have 20 or more instances identified were indicated with a plus sign. Lastly, asterisks indicate any area that had more than 100 instances identified.

\section{Discussion}

It is important to note that the campaign plans were in development while this data collection was in progress. Some of the campaigns changed from the time that the data was collected until it was analyzed. That is why some of the areas are marked as "Not in the current taxonomy." Additionally, the Sciences for Lethality and Protection Campaign level 3 was not defined at the same level as the other campaigns, so the list shown in Fig. 2 was used and analysis was provided data for both the level 3 campaign and the list.

RDECOM had recently completed their survey and there likely was confusion by those who filled out the 2 surveys. RDECOM's survey was designed to understand the competencies at the Research, Development and Engineering Center level as opposed to the laboratory. It was apparent that the confusion as to the difference between the surveys may have impacted some of the competency selections.

Each campaign had data points that were of interest, and recommendations were derived from these indicators. The recommendations for each of the campaigns are discussed separately in the following paragraphs. Overall, of the personnel surveyed, 68\% listed 2 competencies and 46\% 
listed 3 competencies. Only 17\% provided a write-in competency. For the Extramural Basic Research Campaign (Appendix B), there are 3 areas identified as areas where potential gaps might be: Network Sciences, Social Informatics, and Social Sciences were all selected by less than 5 individuals. All areas in this campaign are collaboration areas; 3 areas were identified because they had less than 5 instances chosen.

In the Human Sciences Campaign (Appendix C), there were 3 areas indicated where additional competency may be needed. Two of the areas, Information and Delivery for Effective Learning and Training and Virtual Humans/Avatars were lead areas and had less than 10 instances of the competency selected. Computational Representation of Societies and Cultures is a collaborate area and had less than 5 instances of the competency selected.

The Informational Sciences Campaign (Appendix D) had 13 areas where additional competencies were needed. Seven of these were lead areas: Analysis and Identification of Threats, Stealthy Assessment of Adversarial Networks, Exploitation of Adversarial Network Vulnerabilities, Estimates of Adversarial Dynamics, Forecasts of Mission Environment, Distributed Collaborative Planning and Execution of Missions, and Adaptive Protocols. There were 6 collaborate areas: Effector Phenomenology, Highly Optimized Data Storage on Soldierborne Devices, Risk Assessment of Networks, Planning and Analysis of Military Missions, Intelligent Adaptive Interfaces for Augmented Cognition, and Analysis of Imperfectly Observable Networks. Additionally, there was one lead area that may need additional definition. Sensor Phenomenology had more than 100 instances of competency selected.

Using the Sciences for Lethality and Protection level 3 taxonomy (see Fig. 2), there are 5 competency areas of concern (Appendix E). Two of these are in need of additional competency: Electronic Attack/Protect is a lead area with less than 10 instances and Human Response to Threats is a collaborate area with less than 5 instances. There were 3 areas where additional definition is indicated because more than 100 instances were reported. They are Weapon/Energy Projection, Weapon-Target Interaction, and Prediction/Assessment Tools.

The actual list used to collect data for Sciences for Lethality and Protection had 9 areas indicating that additional competencies were needed. Six of these were lead areas: Decoys and Obscurants, Fire Suppression/Protection, Hit Avoidance Technologies, Non-Lethal Technologies, Projectile Navigation, and Soft-Kill. Additionally, Active Base Protection, Technical Fire Control, and Threat Avoidance were collaborate areas that had less than 5 instances reported.

In the Sciences for Maneuver Campaign (Appendix F), there were only 2 areas that require consideration. Usage Management is a collaborate area that had less than 5 report instances of competency. This indicates that additional competencies are needed in this area. This campaign also had one area, Warfighter Support and Logistics, where more than 20 instances were identified in an area that was designated as a follow area. This is an indication that efforts should be redirected or shuffled to utilize personnel in an area where the laboratory is moving or 
planning to move. Also, 29\% of the instances in Warfighter Support and Logistics were from contractors. Shifting contractor efforts would provide some flexibility without having to recruit.

In the Materials Research Campaign (Appendix G), there were 11 areas in need of additional competencies. Eight of these were areas where ARL has stated that we should lead efforts in the field. Each of these 8 had less than 10 instances of competency: Ultra-Lightweight Metals, Chemical Specific Sensing, Sensor Protection Material, UV Optoelectronics, Quantum Information Science, Computational Biology, Bio-Sensors, and Fatigue. The other 3 areas were collaborate competency areas that had less than 5 instances. They are System Biology, High Strength Conductors, and Energy Absorbers.

The Computational Sciences Campaign (Appendix H) had only 3 areas of concern. Two of these were collaborate areas with less than 5 instances identified. They are Multi-Dimensional Analysis and Model Order Reduction. This campaign also had one area where more than 20 instances were identified in an area that was designated as a follow area. This is an indication that efforts should be redirected or shuffled to utilize personnel in an area where ARL is moving or planning to move. Also, 27\% of the instances in Domain Specific Languages were from contractors.

The Assessment and Analysis Campaign (Appendix I) had 9 competency areas that were identified as needing attention. Six of these were area where a low number of instances were indicated. Three of the 6 were in lead areas where less than 10 instances were selected: Associated Systems Engineering (Smart Systems), Smart Systems, and Smart Technologies. Three were in collaborate areas where less than 5 instances were selected: Smart Platforms and Forces, RAM Assessment, and Effects of Multi- and Cross-Scale Phenomena. Additionally, 3 areas had more than 100 instances identified indicating that the competency area may need more definition. They were Electronic Warfare Assessment, Ballistic Assessment, and Verifying and Validating Assessment Techniques. The first 2 are lead areas, and the other is collaborate.

\section{Conclusions and Recommendations}

It is recognized that the data are not perfect. However, the areas highlighted in this analysis can be examined as areas of concern and a place to begin looking for restructuring the human capital of the laboratory. The survey and data analysis suffered from following on the heels of the RDECOM survey. The close time frame and different purposes of the 2 surveys caused some confusion and likely impacted responses. There is also the chance that some responses were political. Some likely responded with competencies they believed were politically correct, not their actual competency. For all these reasons, the data should be taken with a grain of salt but it does help to focus efforts. One should look at the areas identified as having too few or too many instances of competency and determine if this is actually a fact. 
The study data should also be used by the campaign plans to reevaluate the competencies highlighted in the individual plans. In some cases, it appears that the campaign plans have identified certain competencies that they expect to lead, but there are few to no personnel assigned to these areas. The campaign plans should determine whether these are areas they truly need to lead (in which case, there needs to be future growth in personnel to support these areas) or whether they represent areas to collaborate or follow.

The study data also highlighted a number of competencies where there are a large number of personnel assigned to them. The campaign plans should consider a finer specification of the particular competencies within the larger competency. There was not a consistent number of competencies relative to the number of personnel in each campaign area, which may contribute to large numbers of personnel within a single competency. The effectiveness of this type of study depends on how well the competencies reflect the required skills within the campaign area.

One shortcoming of the study data was that it was impossible to determine whether a particular competency was adequately represented or oversubscribed especially if zero growth in laboratory staff is considered. While the study can provide guidance for those areas that require growth, it appears to be less helpful to defining those areas for contraction.

It is recommended that the survey be completed again once the campaign plans are finalized and the lead, collaborate, and follow areas have been well defined. Additionally, the purpose of the survey should be made clear to all to help prevent political answers. Clear communication of the campaign plan taxonomies, the areas for lead, collaborate, and follow, and the purpose of the survey will be important to improving the data collection. The survey itself was not difficult to complete and with a better understanding of the purpose, the quality of the data will improve.

It is also recommended that a similar assessment be completed for auxiliary and support services to ensure the required support staff is available and functioning. The best scientists in the world cannot make progress without computing services, contracting services, and the associated personnel and human resources. Also, some measure of leadership skills will be of benefit to the organization. ARL must be able to identify those individuals that have the best potential for leading the organization into the campaign plans. 


\section{References}

US Office of Personnel Management: OPM.gov Main, Frequently Asked Questions, USAJOBS, What are KDA's? Washington (DC): US Office of Personnel Management; [accessed 2014 Jan]. http://www.opm.gov/FAQs/QA.aspx?fid=d5e0f29c-fcc1-4ee2-a9f1-67ef78c0dfe4\&pid =e9430deb-2cdc-46a2-8746-0811d78bee9f\&result=1. 


\section{Appendix A. Campaign Competency Selections}

This appendix appears in its original form, without editorial change. 


\begin{tabular}{|l|}
\hline \multicolumn{1}{|c|}{ Extramural Basic Research } \\
\hline Physics \\
\hline Chemical Sciences \\
\hline Biological Sciences \\
\hline Social Sciences \\
\hline Social Informatics \\
\hline Computational Sciences \\
\hline Network Sciences \\
\hline Mathematical Sciences \\
\hline Materials Sciences \\
\hline Electronics \\
\hline Mechanical Sciences \\
\hline Photonics \\
\hline
\end{tabular}




\begin{tabular}{|l|}
\hline \multicolumn{1}{|c|}{ Human Sciences } \\
\hline Molecular biology, biochemistry, genetics and genomics \\
\hline Brain structure-function coupling \\
\hline Computational representation of cognition \\
\hline Sensory perception \\
\hline Physical and cognitive performance and resilience \\
\hline Physical-cognitive interactions \\
\hline Individual differences \\
\hline Environmental effects \\
\hline Multisensory integration \\
\hline State sensing in the real world \\
\hline Learning and experience \\
\hline Computational representation of the human body \\
\hline Motivation and emotion \\
\hline Distributed cognition and decision making \\
\hline Team dynamics \\
\hline Training effectiveness \\
\hline Personnel and leader development \\
\hline Ethics and values \\
\hline Social-cultural interaction \\
\hline Social cognitive networks \\
\hline Organizational structure and design \\
\hline Computational representation of societies and cultures \\
\hline Ergonomics and biomechanics \\
\hline Physical augmentation \\
\hline Multimodal displays and controls \\
\hline Training technologies \\
\hline Usability \\
\hline Implantable materials and devices \\
\hline Brain-computer interaction \\
\hline Cognitive augmentation \\
\hline Human-intelligent systems interaction \\
\hline Wearable computing/systems \\
\hline Human interaction with/in networked systems \\
\hline Virtual humans/avatars \\
\hline Information and delivery for effective learning and training \\
\hline
\end{tabular}




\begin{tabular}{|l|}
\hline \multicolumn{1}{|c|}{ Information Sciences } \\
\hline Sensor phenomenology \\
\hline Effector phenomenology \\
\hline Atmospheric sensors and behavior modeling \\
\hline Highly optimized data storage on soldier-borne devices \\
\hline Uncooperative social sensing \\
\hline Counters to highly stealthy cyber threats \\
\hline Analysis and identification of threat TTPs \\
\hline Risk assessments of networks \\
\hline Stealthy assessment of adversarial networks \\
\hline Exploitation of adversarial network vulnerabilities \\
\hline Attack-resilient cyber operations \\
\hline Pattern recognition and mapping \\
\hline Recognition and classification of human activity \\
\hline Estimates of adversarial dynamics \\
\hline Forecasts of mission environment \\
\hline Planning and analysis of military missions \\
\hline Intelligent control of mission execution \\
\hline Intelligent adaptive interfaces for augmented cognition \\
\hline Analysis and fusion of heterogeneous information \\
\hline Discovery and extraction of information from massive data sets \\
\hline Distributed collaborative planning and execution of missions \\
\hline Trust, consensus and influence \\
\hline Soldier and system role/task allocation \\
\hline Unconventional alternative channels \\
\hline Adaptive protocols \\
\hline Co-evolution/co-dependent behaviors of networks \\
\hline Reconfigurable and self-adaptive networks \\
\hline Analysis of imperfectly observable networks \\
\hline
\end{tabular}




\begin{tabular}{|l|}
\hline \multicolumn{1}{|c|}{ Sciences for Lethality and Protection } \\
\hline Active base protection \\
\hline Active protection systems \\
\hline Armor \\
\hline Counter measures \\
\hline Decoys and obscurants \\
\hline Diagnostics and instrumentation \\
\hline Directed energy technologies \\
\hline Energetic materials and propulsion \\
\hline Fire suppression/protection \\
\hline Guns-launchers \\
\hline Hit avoidance technologies \\
\hline Kinetic penetrators \\
\hline Non-lethal technologies \\
\hline Novel lethal mechanisms \\
\hline Passive base protection \\
\hline Personal protective equipment \\
\hline Projectile maneuverability \\
\hline Projectile navigation \\
\hline Sensors \\
\hline Soft-kill \\
\hline Technical fire control \\
\hline Threat avoidance \\
\hline Warhead, fuze, S and A \\
\hline
\end{tabular}

\begin{tabular}{|l|}
\hline \multicolumn{1}{|c|}{ Sciences for Maneuver } \\
\hline Energy storage \\
\hline Conversion/power generation \\
\hline Distribution/transfer \\
\hline Intelligent energy and power \\
\hline Structures \\
\hline Mechanics and dynamics \\
\hline Actuation and mechanisms \\
\hline Platform concepts \\
\hline Perception \\
\hline Intelligence and control \\
\hline Human machine interaction \\
\hline Reliability \\
\hline Mechanism state awareness (health) \\
\hline Usage management \\
\hline Warfighter support and logistics \\
\hline
\end{tabular}




\begin{tabular}{|l|}
\hline \multicolumn{1}{|c|}{ Materials Research } \\
\hline Advanced platform structures \\
\hline Propulsion \\
\hline Ultra-lightweight metals \\
\hline Polymeric materials \\
\hline Structural energy materials \\
\hline Hybrid, 3d composites \\
\hline Structural materials-multiscale research \\
\hline RF sensing and communication devices \\
\hline Electronic warfare devices \\
\hline RF metamaterials \\
\hline Energy efficient, low power electronics \\
\hline Infrared sensing material and devices \\
\hline Chemical specific sensing \\
\hline Sensor protection material \\
\hline UV optoelectronics \\
\hline High energy and advanced tactical lasers \\
\hline Transformational optics and devices \\
\hline Quantum information science \\
\hline Photonics-multiscale research \\
\hline Energy storage \\
\hline Power generation and energy harvesting \\
\hline MEMS and micropower \\
\hline Fuel cells and fuel processing \\
\hline Power distribution \\
\hline Thermal sciences \\
\hline Novel energy \\
\hline Energy and power-multiscale research \\
\hline Systems biology \\
\hline Synthetic biology \\
\hline computational biology \\
\hline Bio/non-bio integration and interfaces \\
\hline Bio-fuels \\
\hline Bio-sensors \\
\hline Bio and bio-mimetic materials \\
\hline Advanced manufacturing \\
\hline Additive manufacturing \\
\hline Corrosion \\
\hline Fatigue \\
\hline Polymer coatings (CARC) \\
\hline Green materials and processes \\
\hline Energy fields coupled to matter \\
\hline Extreme synthesis of novel materials \\
\hline Lightweight and specialty metals \\
\hline Ceramics and transparents \\
\hline Composites and hybrids \\
\hline
\end{tabular}




\begin{tabular}{|l|}
\hline \multicolumn{1}{|c|}{ Materials Research } \\
\hline Fabrics and wearables \\
\hline High strength conductors \\
\hline Energy absorbers \\
\hline Penetrator and warhead materials \\
\hline Energetics \\
\hline Advanced mechanics \\
\hline Weapons \\
\hline Energy coupled to matter \\
\hline High strain rate and ballistic materials-multiscale research \\
\hline
\end{tabular}

\begin{tabular}{|l|}
\hline \multicolumn{1}{|c|}{ Computational Sciences } \\
\hline Multiscale/interdisciplinary predictive simulation \\
\hline Complex integrated systems \\
\hline Verification, validation and uncertainty quantification \\
\hline Next generation scalable algorithms \\
\hline Multi-dimensional analysis \\
\hline Discrete systems \\
\hline Real-time data access and analytics \\
\hline Model order reduction \\
\hline Tactical high-performance computing systems \\
\hline Data intensive computing architectures \\
\hline Next generation computing systems \\
\hline High performance networking \\
\hline Programming environments \\
\hline Domain specific languages \\
\hline Reusable software \\
\hline Complex systems computing environment \\
\hline
\end{tabular}




\begin{tabular}{|l|}
\hline \multicolumn{1}{|c|}{ Assessment and Analysis } \\
\hline Valuating investments in S and T \\
\hline Forecasting discovery \\
\hline Impact of discovery on innovation \\
\hline Determinants of investment effectiveness \\
\hline Impact of S and T on innovation and competiveness \\
\hline Competitiveness of the S and T workforce \\
\hline Verifying and validating assessment techniques \\
\hline Effects of multi- and cross-scale phenomena \\
\hline Synthesizing disciplines for holistic assessments \\
\hline Ballistic assessment \\
\hline Cyber assessment \\
\hline Electronic warfare assessment \\
\hline System of systems (DOTMLPF) assessment \\
\hline Human factors assessment \\
\hline Ram assessment \\
\hline Smart technologies \\
\hline Smart systems \\
\hline Smart platforms and forces \\
\hline Associated systems engineering (smart systems) \\
\hline
\end{tabular}




\section{Appendix B. Extramural Basic Research Campaign Data}




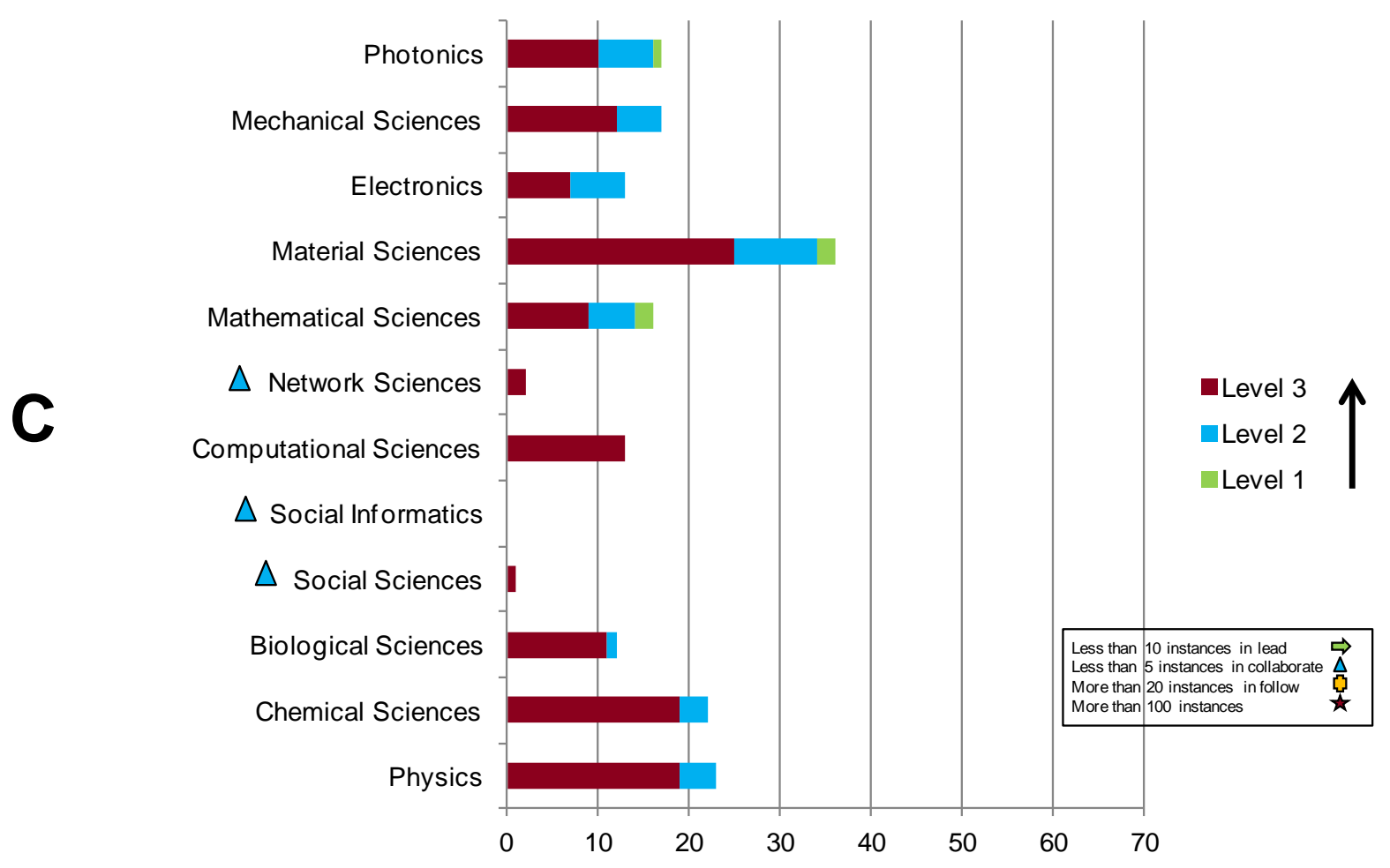

Fig. B-1 Instances chosen for Extramural Basic Research Campaign competencies 
Table B-1 Personnel choosing Extramural Basic Research Campaign competencies

\begin{tabular}{|l|c|c|c|c|}
\hline \multicolumn{1}{|c|}{ Extramural Basic Research } & Civilians & Post Docs & Contractors & Total \\
\hline Photonics & 16 & $\ldots$ & 1 & 17 \\
\hline Mechanical sciences & 15 & $\ldots$ & 2 & 17 \\
\hline Electronics & 13 & $\ldots$ & $\ldots$ & 13 \\
\hline Materials research & 34 & 1 & 1 & 36 \\
\hline Mathematical sciences & 15 & 1 & $\ldots$ & 16 \\
\hline$\wedge$ Network sciences & 2 & $\ldots$ & $\ldots$ & 2 \\
\hline Computational sciences & 9 & 2 & 2 & 13 \\
\hline$\wedge$ Social informatics & 0 & $\ldots$ & $\ldots$ & 0 \\
\hline$\wedge$ Social sciences & 0 & $\ldots$ & 1 & 1 \\
\hline Biological sciences & 11 & $\ldots$ & 1 & 12 \\
\hline Chemical sciences & 14 & 2 & 6 & 22 \\
\hline Physics & 21 & $\ldots$ & 2 & 23 \\
\hline
\end{tabular}

$\wedge$ Less than 5 instances in collaborate

Table B-2 Write-in competencies assigned to Extramural Basic Research Campaign

\begin{tabular}{|l|c|}
\hline \multicolumn{1}{|c|}{ Competency } & Total \\
\hline Fundamental research - laser induced breakdown spectroscopy & 1 \\
\hline Mechanical sciences & 1 \\
\hline Mechanics and materials & 1 \\
\hline Photonics & 4 \\
\hline Physics & 2 \\
\hline Statistical analysis & 1 \\
\hline Theoretical and numerical chemistry & 1 \\
\hline Quantum chemistry & 1 \\
\hline Optimization in chemical compound space & 35 \\
\hline Fundamental research - extramural basic research & 1 \\
\hline Condense matter physics & 2 \\
\hline Device physics & 1 \\
\hline Multidisciplinary organic synthetic chemical and biotechnology & 1 \\
\hline Multidisciplinary analytical chemistry electrochemistry and bio & 1 \\
\hline Multidisciplinary analytical chemistry/spectroscopy and biotechnology & 2 \\
\hline Multidisciplinary physics and biotechnology & 1 \\
\hline Photonics and lasers & 1 \\
\hline Quantum sciences-basic physics & \\
\hline
\end{tabular}




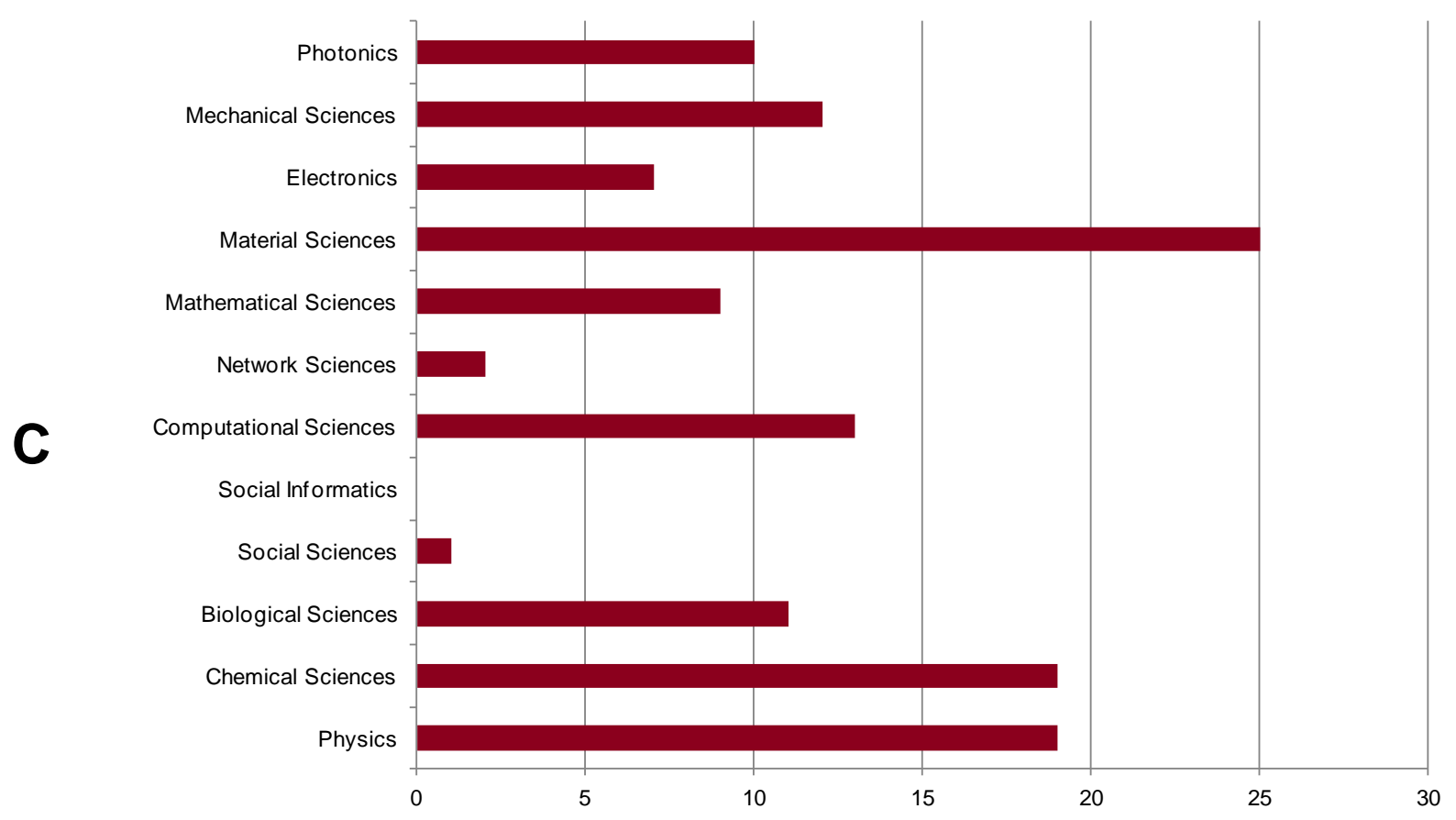

Fig. B-2 Instances chosen for Extramural Basic Research Campaign competencies for proficiency level 3 only

Table B-3 Personnel choosing Extramural Basic Research Campaign competencies for proficiency level 3 only

\begin{tabular}{|l|c|c|c|c|}
\hline \multicolumn{1}{|c|}{ Extramural Basic Research } & Civilians & Post Docs & Contractors & Total \\
\hline Photonics & 10 & $\ldots$ & $\ldots$ & 10 \\
\hline Mechanical sciences & 12 & $\ldots$ & $\ldots$ & 12 \\
\hline Electronics & 7 & $\ldots$ & $\ldots$ & 7 \\
\hline Materials research & 25 & $\ldots$ & $\ldots$ & 25 \\
\hline Mathematical sciences & 9 & $\ldots$ & $\ldots$ & 9 \\
\hline$\wedge$ Network sciences & 2 & $\ldots$ & $\ldots$ & 2 \\
\hline Computational sciences & 11 & 1 & 1 & 13 \\
\hline$\wedge$ Social informatics & 0 & $\ldots$ & $\ldots$ & 0 \\
\hline$\wedge$ Social sciences & 0 & $\ldots$ & 1 & 1 \\
\hline Biological sciences & 10 & $\ldots$ & 1 & 11 \\
\hline Chemical sciences & 14 & $\ldots$ & 5 & 19 \\
\hline Physics & 19 & $\ldots$ & $\ldots$ & 19 \\
\hline
\end{tabular}

$\wedge$ Less than 5 instances in collaborate 


\section{Appendix C. Human Sciences Campaign Data}




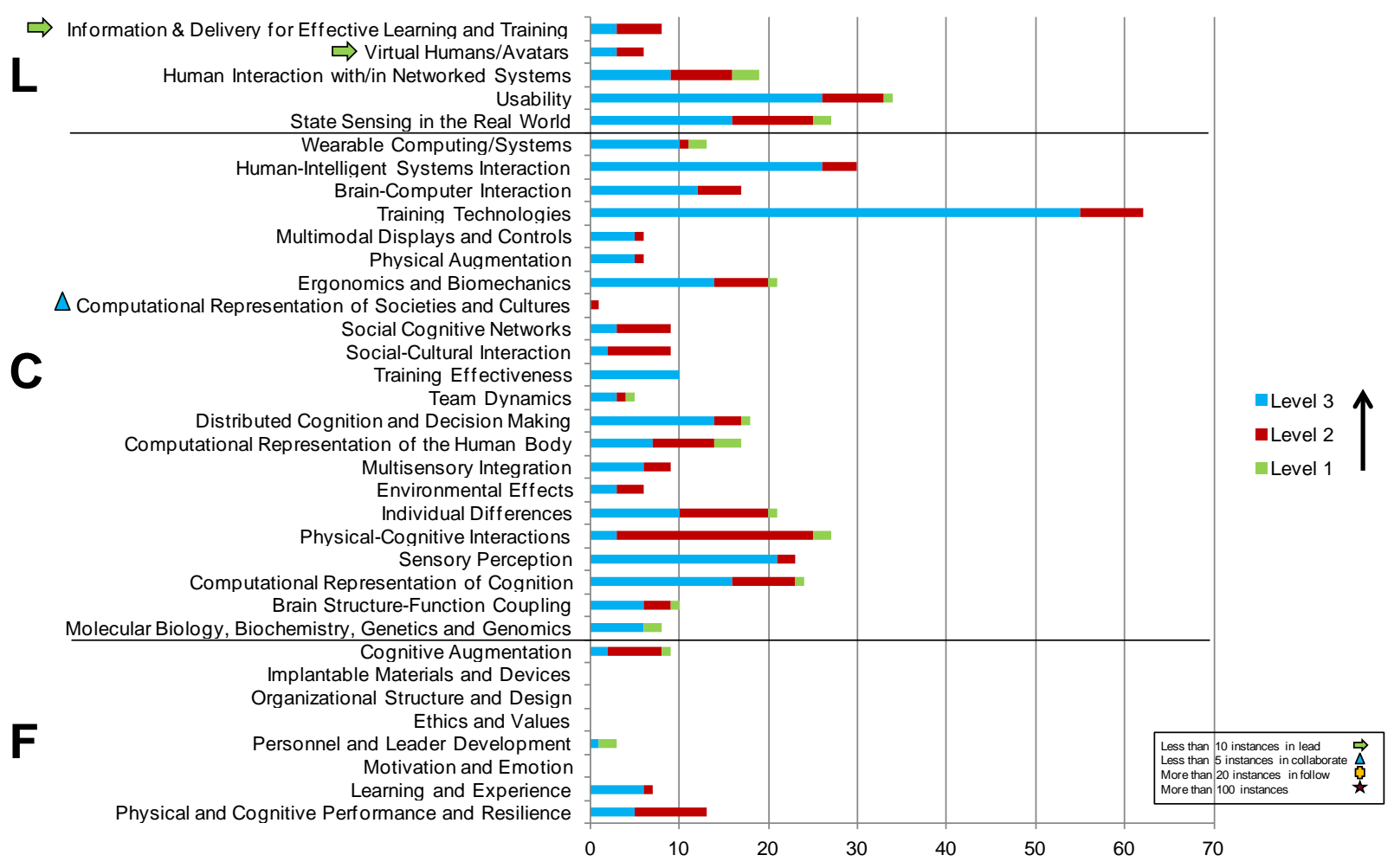

Fig. C-1 Instances chosen for Human Sciences Campaign Competencies 
Table C-1 Personnel choosing Human Sciences Campaign competencies

\begin{tabular}{|c|c|c|c|c|}
\hline $\begin{array}{l}\text { Human Sciences } \\
\end{array}$ & Civilians & Post Docs & Contractors & Total \\
\hline$>$ Information and delivery for effective learning and training & 8 & $\ldots$ & $\ldots$ & 8 \\
\hline >Virtual humans/avatars & 6 & $\ldots$ & $\ldots$ & 6 \\
\hline Human interaction with/in networked systems & 13 & 2 & 4 & 19 \\
\hline Usability & 33 & $\ldots$ & 1 & 34 \\
\hline State sensing in the real world & 9 & 10 & 8 & 27 \\
\hline Wearable computing/systems & 3 & 3 & 7 & 13 \\
\hline Human-intelligent systems interaction & 12 & 9 & 9 & 30 \\
\hline Brain-computer interaction & 5 & 7 & 5 & 17 \\
\hline Training technologies & 42 & $\ldots$ & 20 & 62 \\
\hline Multimodal displays and controls & 6 & $\ldots$ & $\ldots$ & 6 \\
\hline Physical augmentation & 4 & 2 & $\ldots$ & 6 \\
\hline Ergonomics and biomechanics & 15 & 3 & 3 & 21 \\
\hline$\wedge$ Computational representation of societies and cultures & 1 & $\ldots$ & $\ldots$ & 1 \\
\hline Social cognitive networks & 8 & 1 & $\ldots$ & 9 \\
\hline Social-cultural interaction & 8 & $\ldots$ & 1 & 9 \\
\hline Training effectiveness & 10 & $\ldots$ & $\ldots$ & 10 \\
\hline Team dynamics & 3 & 2 & $\ldots$ & 5 \\
\hline Distributed cognition and decision making & 11 & 3 & 4 & 18 \\
\hline Computational representation of the human body & 11 & $\ldots$ & 6 & 17 \\
\hline Multisensory integration & 9 & $\ldots$ & $\ldots$ & 9 \\
\hline Environmental effects & 5 & 1 & $\ldots$ & 6 \\
\hline Individual differences & 13 & 4 & 4 & 21 \\
\hline Physical-cognitive interactions & 27 & $\ldots$ & $\ldots$ & 27 \\
\hline Sensory perception & 23 & $\ldots$ & $\ldots$ & 23 \\
\hline Computational representation of cognition & 10 & 9 & 5 & 24 \\
\hline Brain structure-function coupling & 4 & 4 & 2 & 10 \\
\hline Molecular biology, biochemistry, genetics and genomics & 7 & $\ldots$ & 1 & 8 \\
\hline Cognitive augmentation & 8 & 1 & $\ldots$ & 9 \\
\hline Implantable materials and devices & 0 & $\ldots$ & $\ldots$ & 0 \\
\hline Organizational structure and design & 0 & $\ldots$ & $\ldots$ & 0 \\
\hline Ethics and values & 0 & $\ldots$ & $\ldots$ & 0 \\
\hline Personnel and leader development & 3 & $\ldots$ & $\ldots$ & 3 \\
\hline Motivation and emotion & 0 & $\ldots$ & $\ldots$ & 0 \\
\hline Learning and experience & 5 & $\ldots$ & 2 & 7 \\
\hline Physical and cognitive performance and resilience & 12 & $\ldots$ & 1 & 13 \\
\hline
\end{tabular}

$>$ Less than 10 instances in lead

$\wedge$ Less than 5 instances in collaborate 
Table C-2 Write-in competencies assigned to Human Sciences Campaign

\begin{tabular}{|l|c|}
\hline \multicolumn{1}{|c|}{ Competency } & Total \\
\hline Audiology & 1 \\
\hline Traumatic brain injury & 1 \\
\hline Adaptive training research_intelligent tutoring systems & 1 \\
\hline Dismounted soldier training & 7 \\
\hline Ground platform training & 1 \\
\hline Human factors integration tools & 2 \\
\hline Human sciences-human use review & 1 \\
\hline Information and delivery for effective learning & 1 \\
\hline Intelligent tutoring systems—computer architectures & 1 \\
\hline Intelligent tutoring systems-human factors & 1 \\
\hline Intelligent tutoring systems-human systems interaction & 1 \\
\hline Large scale distributed simulation for collective training & 1 \\
\hline Live training and testing & 2 \\
\hline Olfactory adaptation & 1 \\
\hline Quantifying know transfer using sim-based trn methods & 2 \\
\hline Simulation and training (dismounted soldier training) & 1 \\
\hline Simulation and training (program management) & 9 \\
\hline Small arms research & 6 \\
\hline Synthetic environment for training & 2 \\
\hline
\end{tabular}

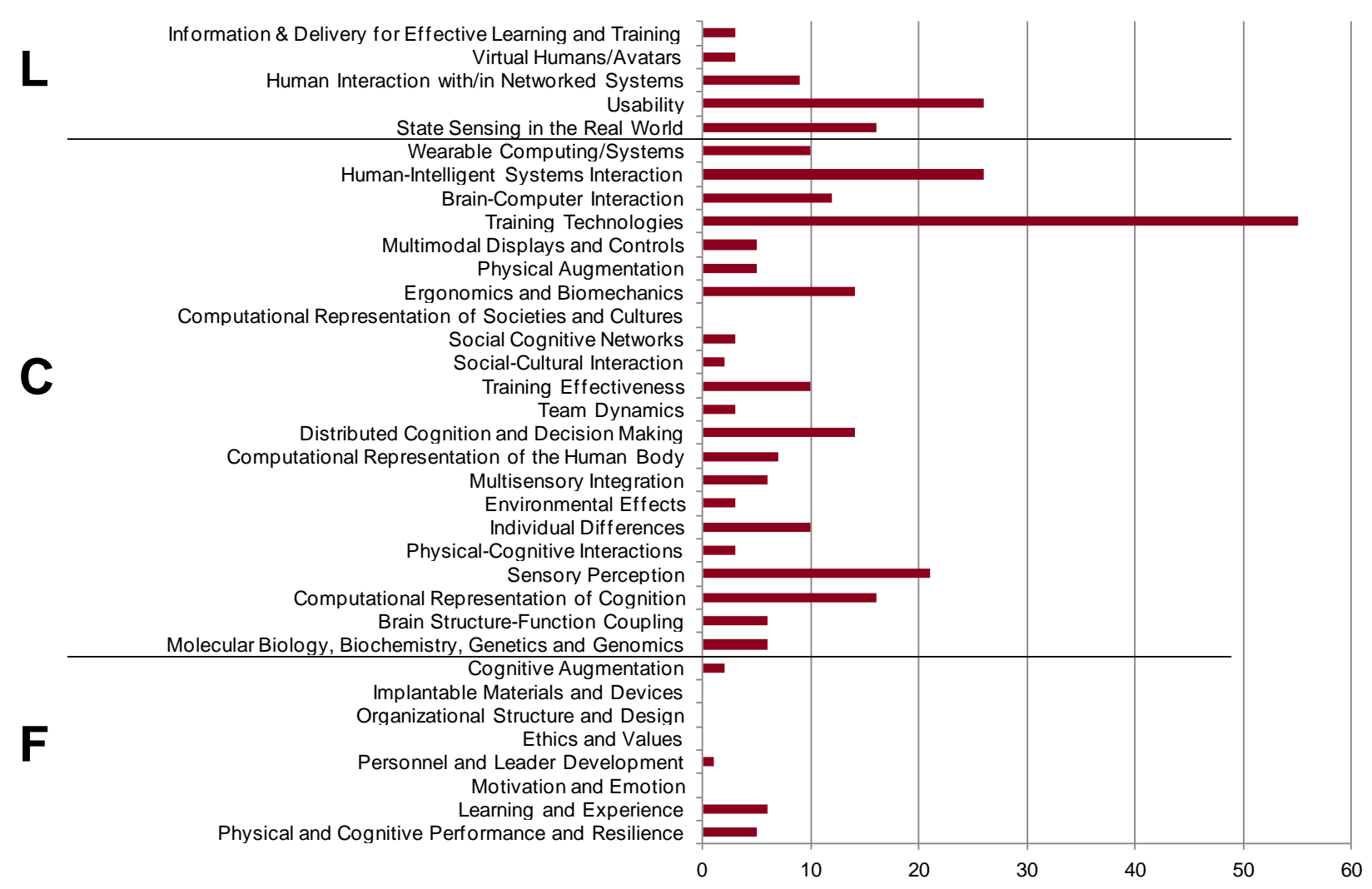

Fig. C-2 Instances chosen for Human Sciences Campaign Competencies for proficiency level 3 only 
Table C-3 Personnel choosing Human Sciences Campaign competencies for proficiency level 3 only

\begin{tabular}{|c|c|c|c|c|}
\hline Human Sciences & Civilians & Post Docs & Contractors & Total \\
\hline$>$ Information and delivery for effective learning and training & 3 & $\ldots$ & $\ldots$ & 3 \\
\hline$>$ Virtual humans/avatars & 3 & $\ldots$ & $\ldots$ & 3 \\
\hline Human interaction with/in networked systems & 7 & $\ldots$ & 2 & 9 \\
\hline Usability & 25 & $\ldots$ & 1 & 26 \\
\hline State sensing in the real world & 5 & 5 & 6 & 16 \\
\hline Wearable computing/systems & 3 & 1 & 6 & 10 \\
\hline Human-intelligent systems interaction & 11 & 8 & 7 & 26 \\
\hline Brain-computer interaction & 4 & 5 & 3 & 12 \\
\hline Training technologies & 39 & & 16 & 55 \\
\hline Multimodal displays and controls & 5 & $\ldots$ & $\ldots$ & 5 \\
\hline Physical augmentation & 3 & 2 & $\ldots$ & 5 \\
\hline Ergonomics and biomechanics & 11 & 3 & $\ldots$ & 14 \\
\hline$\wedge$ Computational representation of societies and cultures & 0 & & $\ldots$ & 0 \\
\hline Social cognitive networks & 2 & 1 & $\ldots$ & 3 \\
\hline Social-cultural interaction & 1 & $\ldots$ & 1 & 2 \\
\hline Training effectiveness & 10 & $\ldots$ & $\ldots$ & 10 \\
\hline Team dynamics & 3 & $\ldots$ & $\ldots$ & 3 \\
\hline Distributed cognition and decision making & 8 & 2 & 4 & 14 \\
\hline Computational representation of the human body & 4 & $\ldots$ & 3 & 7 \\
\hline Multisensory integration & 6 & $\ldots$ & $\ldots$ & 6 \\
\hline Environmental effects & 3 & $\ldots$ & $\ldots$ & 3 \\
\hline Individual differences & 8 & 1 & 1 & 10 \\
\hline Physical-cognitive interactions & 3 & $\ldots$ & $\ldots$ & 3 \\
\hline Sensory perception & 20 & 1 & $\ldots$ & 21 \\
\hline Computational representation of cognition & 6 & 6 & 4 & 16 \\
\hline Brain structure-function coupling & 3 & 2 & 1 & 6 \\
\hline Molecular biology, biochemistry, genetics and genomics & 5 & $\ldots$ & 1 & 6 \\
\hline Cognitive augmentation & 2 & $\ldots$ & $\ldots$ & 2 \\
\hline Implantable materials and devices & 0 & $\ldots$ & $\ldots$ & 0 \\
\hline Organizational structure and design & 0 & $\ldots$ & $\ldots$ & 0 \\
\hline Ethics and values & 0 & $\ldots$ & $\ldots$ & 0 \\
\hline Personnel and leader development & 0 & $\ldots$ & 1 & 1 \\
\hline Motivation and emotion & 0 & $\ldots$ & $\ldots$ & 0 \\
\hline Learning and experience & 4 & $\ldots$ & 2 & 6 \\
\hline Physical and cognitive performance and resilience & 5 & $\ldots$ & $\ldots$ & 5 \\
\hline
\end{tabular}

$>$ Less than 10 instances in lead

$\wedge$ Less than 5 instances in collaborate 
INTENTIONALLY LEFT BLANK. 


\section{Appendix D. Information Sciences Campaign Data}




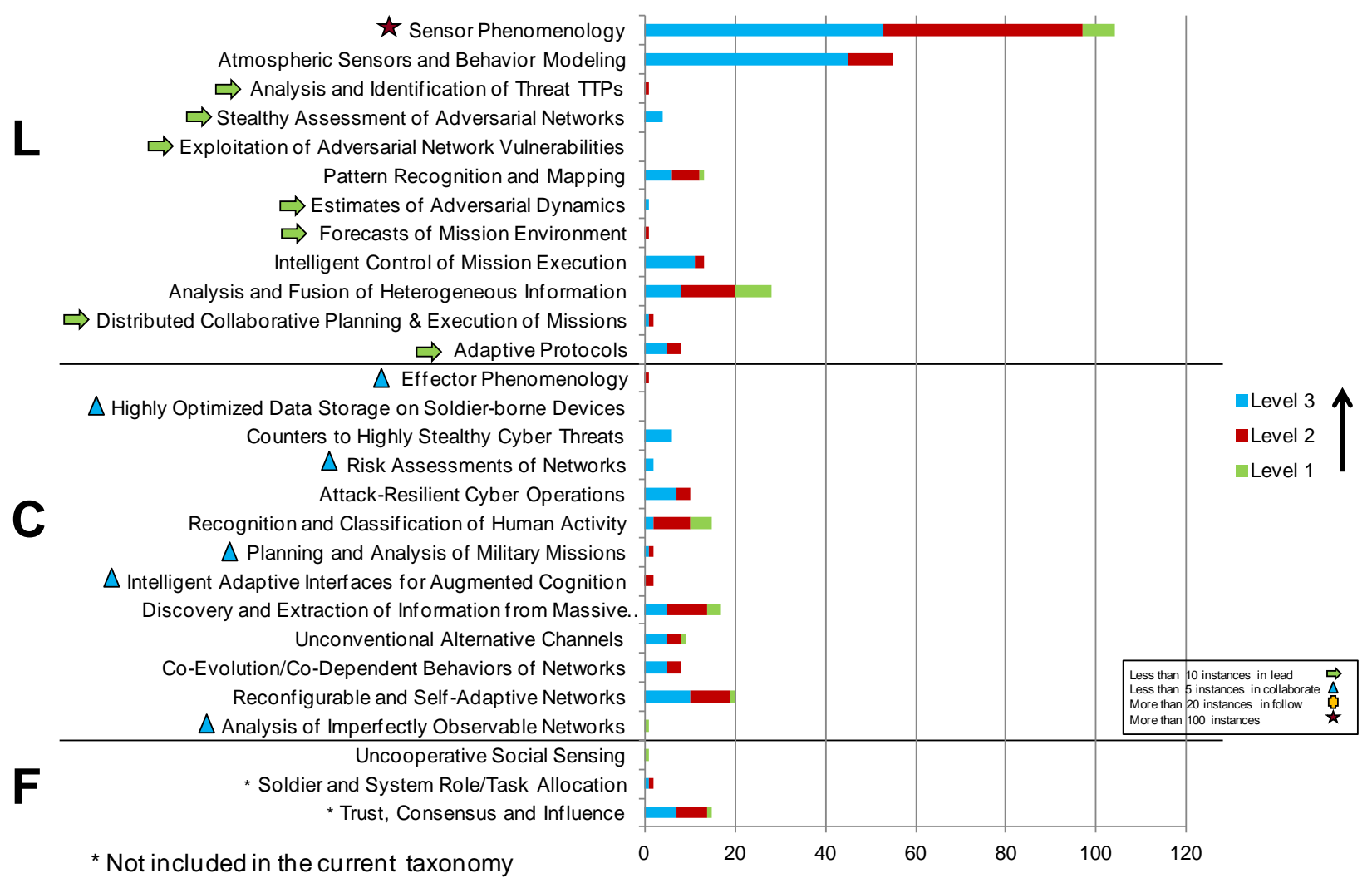

Fig. D-1 Instances chosen for Information Sciences Campaign competencies 
Table D-1 Personnel choosing Information Sciences Campaign competencies

\begin{tabular}{|l|c|c|c|c|}
\hline \multicolumn{1}{|c|}{ Information Sciences } & Civilians & Post Docs & Contractors & Total \\
\hline *Sensor phenomenology & 98 & 1 & 5 & 104 \\
\hline Atmospheric sensors and behavior modeling & 42 & 8 & 5 & 55 \\
\hline$>$ Analysis and identification of threat TTPs & 1 & $\ldots$ & $\ldots$ & 1 \\
\hline$>$ Stealthy assessment of adversarial networks & 4 & $\ldots$ & $\ldots$ & 4 \\
\hline$>$ Exploitation of adversarial network vulnerabilities & 0 & $\ldots$ & $\ldots$ & 0 \\
\hline Pattern recognition and mapping & 12 & $\ldots$ & 1 & 13 \\
\hline$>$ Estimates of adversarial dynamics & 1 & $\ldots$ & $\ldots$ & 1 \\
\hline$>$ Forecasts of mission environment & 1 & $\ldots$ & $\ldots$ & 1 \\
\hline Intelligent control of mission execution & 11 & 1 & 1 & 13 \\
\hline Analysis and fusion of heterogeneous information & 26 & $\ldots$ & 2 & 28 \\
\hline$>$ Distributed collaborative planning and execution of missions & 2 & $\ldots$ & $\ldots$ & 2 \\
\hline$>$ Adaptive protocols & 7 & 1 & $\ldots$ & 8 \\
\hline$\wedge$ Effector phenomenology & 1 & $\ldots$ & $\ldots$ & 1 \\
\hline$\wedge$ Highly optimized data storage on soldier-borne devices & 0 & $\ldots$ & $\ldots$ & 0 \\
\hline Counters to highly stealthy cyber threats & 6 & $\ldots$ & $\ldots$ & 6 \\
\hline$\wedge$ Risk assessments of networks & 2 & $\ldots$ & $\ldots$ & 2 \\
\hline Attack-resilient cyber operations & 10 & $\ldots$ & $\ldots$ & 10 \\
\hline Recognition and classification of human activity & 15 & $\ldots$ & $\ldots$ & 15 \\
\hline$\wedge$ Planning and analysis of military missions & 2 & $\ldots$ & $\ldots$ & 2 \\
\hline$\wedge$ Intelligent adaptive interfaces for augmented cognition & 2 & $\ldots$ & $\ldots$ & 2 \\
\hline Discovery and extraction of information from massive data sets & 14 & 1 & 2 & 17 \\
\hline Unconventional alternative channels & 7 & 1 & 1 & 9 \\
\hline Co-evolution/co-dependent behaviors of networks & 7 & 1 & $\ldots$ & 8 \\
\hline Reconfigurable and self-adaptive networks & 15 & 1 & 4 & 20 \\
\hline$\wedge$ Analysis of imperfectly observable networks & 1 & $\ldots$ & $\ldots$ & 1 \\
\hline Uncooperative social sensing & 11 & 3 & 1 & 15 \\
\hline \#Trust, consensus and influence & 2 & $\ldots$ & $\ldots$ & 2 \\
\hline \#Soldier and system role/task allocation & & $\ldots$ & $\ldots$ & 1 \\
\hline
\end{tabular}

*More than 100 instances

$>$ Less than 10 instances in lead

$\wedge$ Less than 5 instances in collaborate

\#Not in the current taxonomy. 
Table D-2 Write-in competencies assigned to the Informational Sciences Campaign

\begin{tabular}{|l|c|}
\hline \multicolumn{1}{|c|}{ Competency } & Total \\
\hline Multi-modal sensor database & 1 \\
\hline Fusion of multi-modal signature for human detection & 1 \\
\hline Distributed processing across networks & 2 \\
\hline Interoperability across sensors and networks & 2 \\
\hline Distributed networks & 1 \\
\hline Network signal processing & 1 \\
\hline Cross modal face recognition & 1 \\
\hline Distributed network processing & 1 \\
\hline Distributed networks & 1 \\
\hline Distributed processing across networks & 1 \\
\hline Fusion of multi-modal signature for human detection & 1 \\
\hline Hyperspectral sensor phenomenology & 1 \\
\hline Image sampling and super-resolution & 1 \\
\hline Interoperability across sensors and networks & 2 \\
\hline Interoperability of RF systems & 1 \\
\hline IR and visible video fusion & 1 \\
\hline Multi-modal sensor database & 1 \\
\hline Networks signal processing & 1 \\
\hline Nonlinear classification and support vector machines & 1 \\
\hline Sensors & 1 \\
\hline Sensors and bio-inspired controls & 1 \\
\hline Sensors and signal processing & 1 \\
\hline Signal processing algorithms & 1 \\
\hline Signal processing and cognitive radar & 2 \\
\hline Sparse dictionary methods & 1 \\
\hline Optimal networking & 1 \\
\hline Atmospheric characterization and modeling & 1 \\
\hline Infrastructure networking & 1 \\
\hline Infrastructure networking documentation & 1 \\
\hline Infrastructure networking/unclassified & 1 \\
\hline Infrastructure networking/unclassified and classified & 1 \\
\hline Software defined networking & 1 \\
\hline Software defined networking (GENI system) & 1 \\
\hline Sensors & 1 \\
\hline Networks signal processing & 1 \\
\hline
\end{tabular}




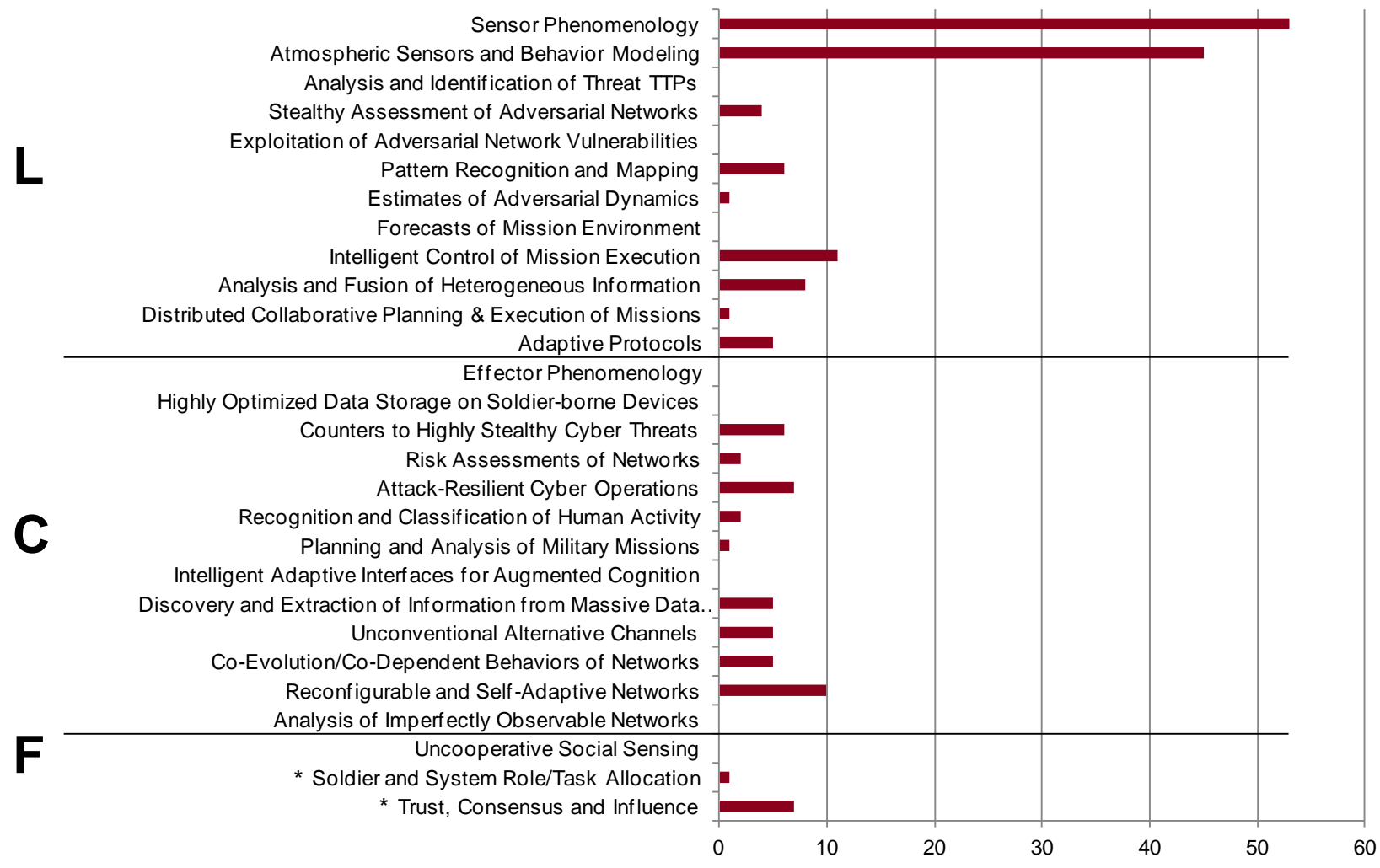

* Not included in the current taxonomy

Fig. D-2 Instances chosen for Information Sciences Campaign competencies for proficiency level 3 only 
Table D-3 Personnel choosing Information Sciences Campaign competencies for proficiency level 3 only

\begin{tabular}{|c|c|c|c|c|}
\hline Information Sciences & Civilians & Post Docs & Contractors & Total \\
\hline *Sensor phenomenology & 51 & $\ldots$ & 2 & 53 \\
\hline Atmospheric sensors and behavior modeling & 41 & 2 & 2 & 45 \\
\hline$>$ Analysis and identification of threat TTPs & 0 & $\ldots$ & $\ldots$ & 0 \\
\hline$>$ Stealthy assessment of adversarial networks & 4 & $\ldots$ & $\ldots$ & 4 \\
\hline$>$ Exploitation of adversarial network vulnerabilities & 0 & $\ldots$ & $\ldots$ & 0 \\
\hline Pattern recognition and mapping & 6 & $\ldots$ & $\ldots$ & 6 \\
\hline$>$ Estimates of adversarial dynamics & 1 & $\ldots$ & $\ldots$ & 1 \\
\hline$>$ Forecasts of mission environment & 0 & $\ldots$ & $\ldots$ & 0 \\
\hline Intelligent control of mission execution & 9 & 1 & 1 & 11 \\
\hline Analysis and fusion of heterogeneous information & 8 & $\ldots$ & $\ldots$ & 8 \\
\hline$>$ Distributed collaborative planning \& execution of missions & 1 & $\ldots$ & $\ldots$ & 1 \\
\hline >Adaptive protocols & 4 & 1 & $\ldots$ & 5 \\
\hline ^Effector phenomenology & 0 & $\ldots$ & $\ldots$ & 0 \\
\hline ^Highly optimized data storage on soldier-borne devices & 0 & $\ldots$ & $\ldots$ & 0 \\
\hline Counters to highly stealthy cyber threats & 6 & $\ldots$ & $\ldots$ & 6 \\
\hline$\wedge$ Risk assessments of networks & 2 & $\ldots$ & $\ldots$ & 2 \\
\hline Attack-resilient cyber operations & 7 & $\ldots$ & $\ldots$ & 7 \\
\hline Recognition and classification of human activity & 2 & $\ldots$ & $\ldots$ & 2 \\
\hline$\wedge$ Planning and analysis of military missions & 1 & $\ldots$ & $\ldots$ & 1 \\
\hline ^Intelligent adaptive interfaces for augmented cognition & 0 & $\ldots$ & $\ldots$ & 0 \\
\hline Discovery and extraction of information from massive data sets & 5 & $\ldots$ & $\ldots$ & 5 \\
\hline Unconventional alternative channels & 3 & 1 & 1 & 5 \\
\hline Co-evolution/co-dependent behaviors of networks & 5 & $\ldots$ & $\ldots$ & 5 \\
\hline Reconfigurable and self-adaptive networks & 8 & $\ldots$ & 2 & 10 \\
\hline$\wedge$ Analysis of imperfectly observable networks & 0 & $\ldots$ & $\ldots$ & 0 \\
\hline Uncooperative social sensing & 0 & $\ldots$ & $\ldots$ & 0 \\
\hline \#Trust, consensus and influence & 5 & 1 & 1 & 7 \\
\hline \#Soldier and system role/task allocation & 1 & $\ldots$ & $\ldots$ & 1 \\
\hline
\end{tabular}

*More than 100 instances

$>$ Less than 10 instances in lead

$\wedge$ Less than 5 instances in collaborate

\#Not in the current taxonomy 


\section{Appendix E. Sciences for Lethality and Protection Campaign Data}




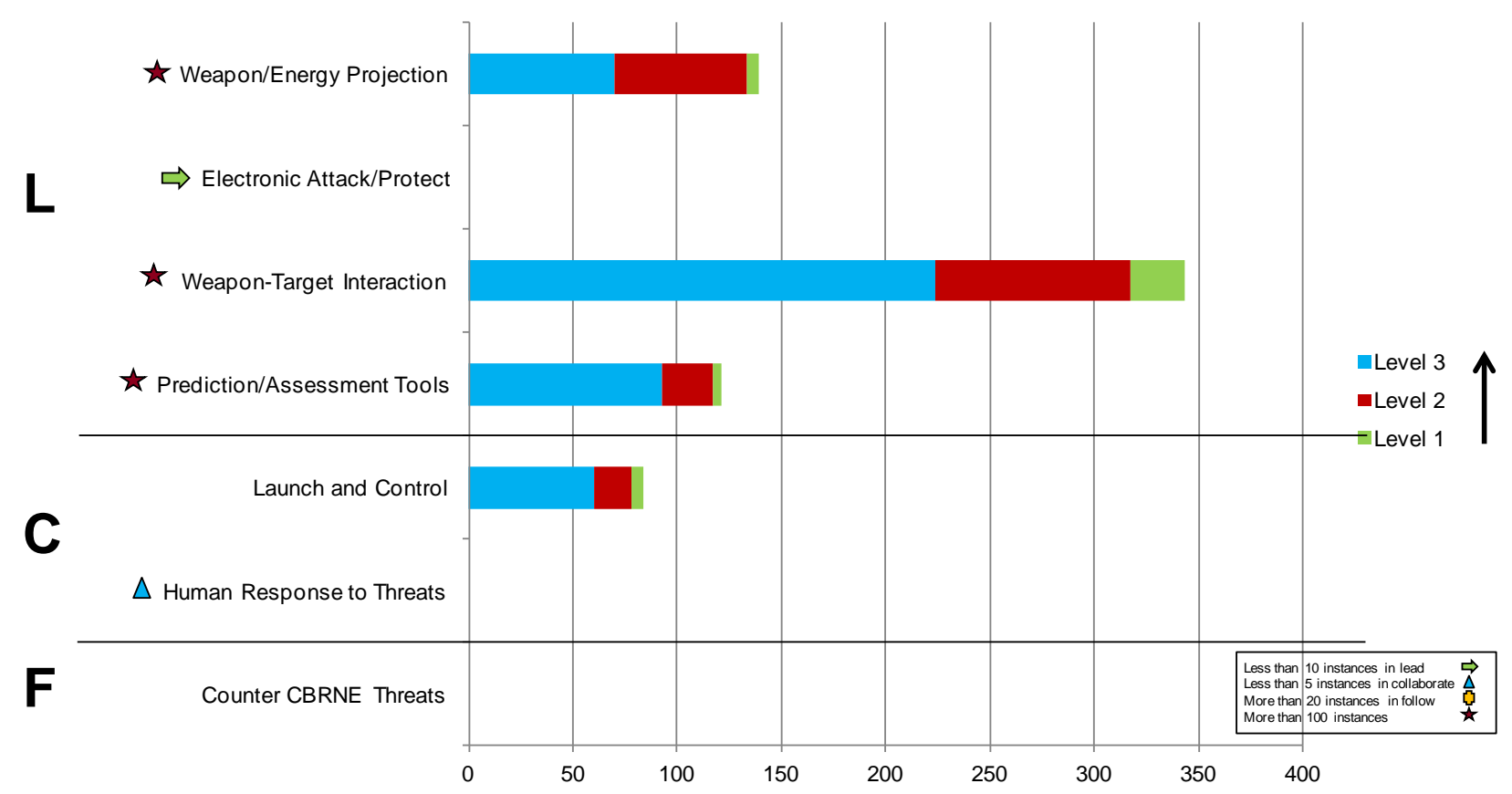

Fig. E-1 Instances chosen for Sciences for Lethality and Protection Campaign competencies as defined by campaign level 3 taxonomy

Table E-1 Personnel choosing Sciences for Lethality and Protection Campaign competencies as defined by level 3 taxonomy

\begin{tabular}{|l|c|c|c|c|}
\hline \multicolumn{1}{|c|}{ Sciences for Lethality and Protection } & Civilians & Post Docs & Contractors & Total \\
\hline *Weapon/energy projection & 121 & $\ldots$ & 18 & 139 \\
\hline Electronic attack/protect & $\ldots$ & $\ldots$ & $\ldots$ & $\ldots$ \\
\hline *Weapon-target interaction & 264 & 0 & 79 & 343 \\
\hline *Prediction/assessment tools & 85 & $\ldots$ & 36 & 121 \\
\hline Launch and control & 57 & $\ldots$ & 27 & 84 \\
\hline$\wedge$ Human response to threats & $\ldots$ & $\ldots$ & $\ldots$ & $\ldots$ \\
\hline Counter CBRNE threats & $\ldots$ & $\ldots$ & $\ldots$ & $\ldots$ \\
\hline
\end{tabular}

*More than 100 instances

$\wedge$ Less than 5 instances in collaborate 


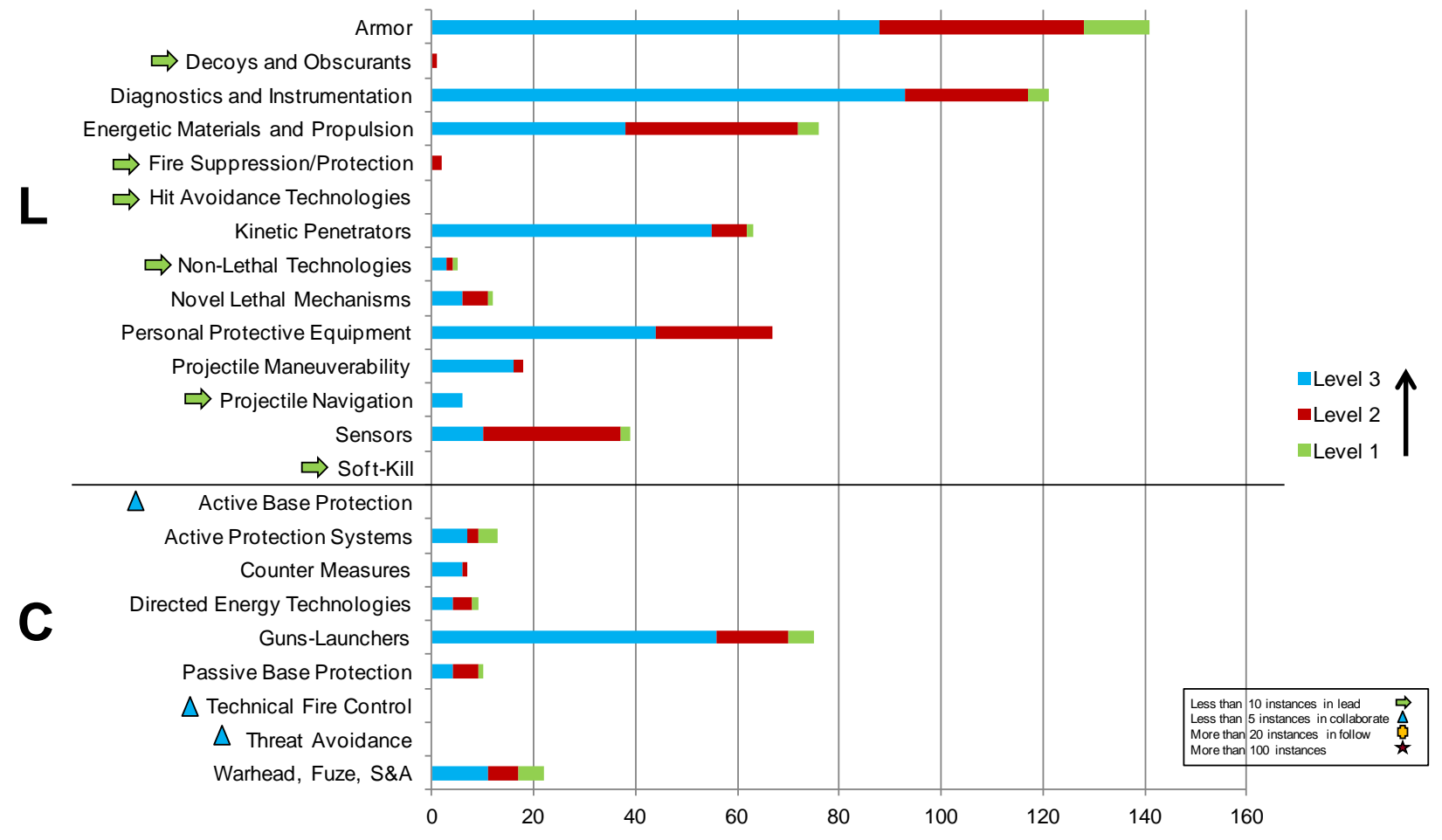

Fig. E-2 Instances chosen for Sciences for Lethality and Protection Campaign Competencies from list provided 
Table E-2 Personnel choosing Sciences for Lethality and Protection Campaign competencies from list provided

\begin{tabular}{|l|c|c|c|c|}
\hline \multicolumn{1}{|c|}{ Sciences for Lethality and Protection } & Civilians & Post Docs & Contractors & Total \\
\hline Armor & 113 & 1 & 27 & 141 \\
\hline$>$ Decoys and obscurants & 1 & $\ldots$ & $\ldots$ & 1 \\
\hline Diagnostics and instrumentation & 85 & $\ldots$ & 36 & 121 \\
\hline Energetic materials and propulsion & 63 & $\ldots$ & 13 & 76 \\
\hline$>$ Fire suppression/protection & 2 & $\ldots$ & $\ldots$ & 2 \\
\hline$>$ Hit avoidance technologies & 0 & $\ldots$ & $\ldots$ & 0 \\
\hline Kinetic penetrators & 50 & $\ldots$ & 13 & 63 \\
\hline$>$ Non-lethal technologies & 5 & $\ldots$ & $\ldots$ & 5 \\
\hline Novel lethal mechanisms & 12 & $\ldots$ & $\ldots$ & 12 \\
\hline Personal protective equipment & 49 & $\ldots$ & 18 & 67 \\
\hline Projectile maneuverability & 16 & $\ldots$ & 2 & 18 \\
\hline$>$ Projectile navigation & 6 & $\ldots$ & $\ldots$ & 6 \\
\hline Sensors & 39 & $\ldots$ & $\ldots$ & 39 \\
\hline$>$ Soft-kill & 0 & $\ldots$ & $\ldots$ & 0 \\
\hline$\wedge$ Active base protection & 0 & $\ldots$ & $\ldots$ & 0 \\
\hline Active protection systems & 12 & $\ldots$ & 1 & 13 \\
\hline Counter measures & 7 & $\ldots$ & $\ldots$ & 7 \\
\hline Directed energy technologies & 9 & $\ldots$ & $\ldots$ & 9 \\
\hline Guns-launchers & 59 & $\ldots$ & 16 & 75 \\
\hline Passive base protection & 10 & $\ldots$ & $\ldots$ & 10 \\
\hline$\wedge$ Technical fire control & 0 & $\ldots$ & $\ldots$ & 0 \\
\hline$\wedge$ Threat avoidance & 0 & $\ldots$ & $\ldots$ & 0 \\
\hline Warhead, fuze, S and A & 22 & $\ldots$ & $\ldots$ & 22 \\
\hline
\end{tabular}

$>$ Less than 10 instances in lead

$\wedge$ Less than 5 instances in collaborate

Table E-3 Write-in competencies assigned to Sciences for Lethality and Protection Campaign

\begin{tabular}{|l|c|}
\hline \multicolumn{1}{|c|}{ Competency } & Total \\
\hline Adhesive bonding and coating of energetics & 1 \\
\hline Novel protection mechanisms & 1 \\
\hline Life, safety, and health—ionizing and non-ionizing radiation & 1 \\
\hline Life, safety, and health—occupational health/exposure control & 1 \\
\hline Life, safety, and health—safety systems & 1 \\
\hline RF electronic attack and directed energy & 1 \\
\hline On-chip energetics & 2 \\
\hline
\end{tabular}




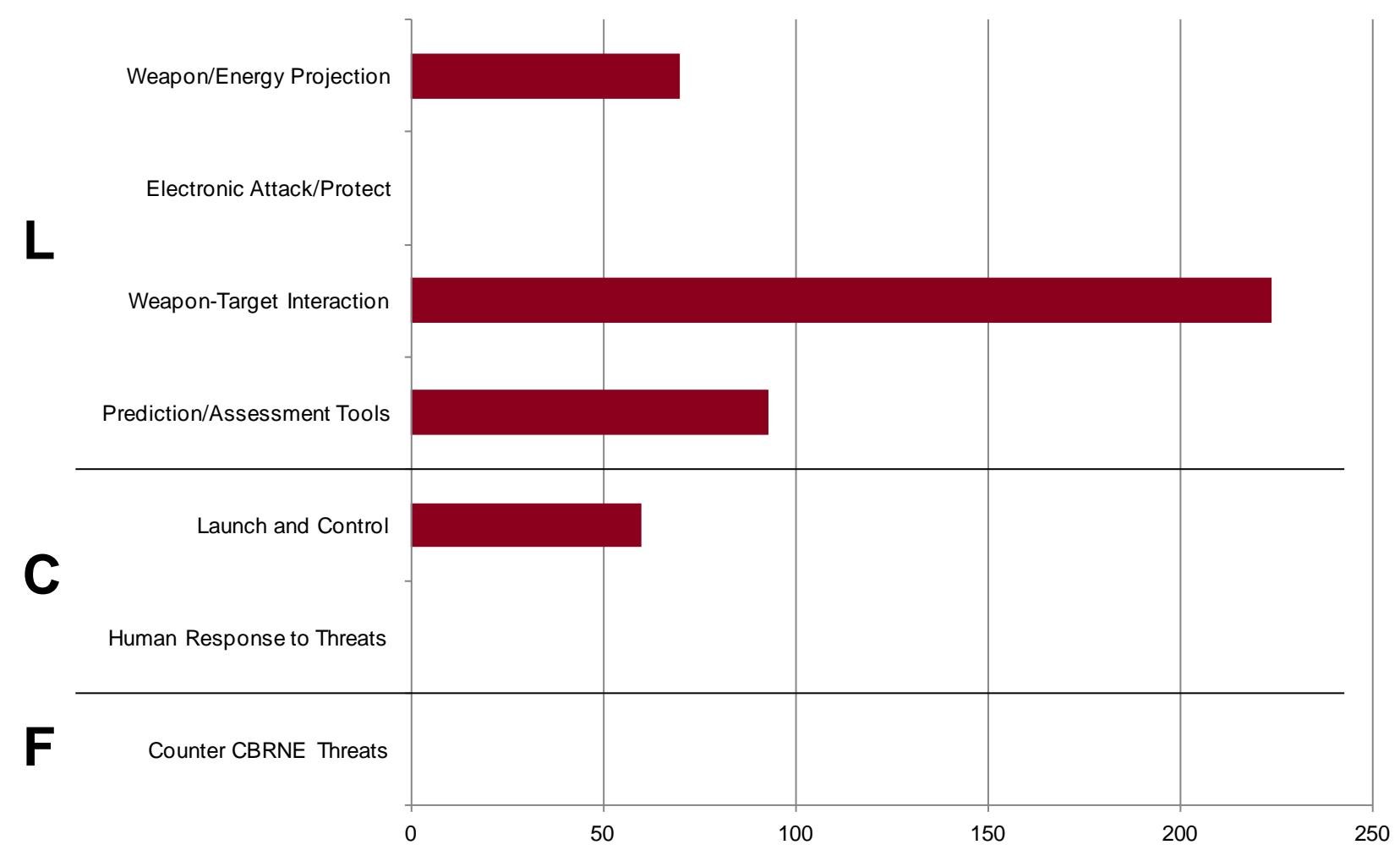

Fig. E-3 Instances chosen for Sciences for Lethality and Protection Campaign for proficiency level 3 only (campaign level 3 taxonomy)

Table E-4 Personnel choosing Sciences for Lethality and Protection Campaign competencies for proficiency level 3 only (campaign level 3 taxonomy)

\begin{tabular}{|l|c|c|c|c|}
\hline \multicolumn{1}{|c|}{ Sciences for Lethality and Protection } & Civilians & Post Docs & Contractors & Total \\
\hline *Weapon/energy projection & 70 & $\ldots$ & $\ldots$ & 70 \\
\hline$>$ Electronic attack/protect & 0 & $\ldots$ & $\ldots$ & $\ldots$ \\
\hline *Weapon-target interaction & 224 & $\ldots$ & $\ldots$ & 224 \\
\hline *Prediction/assessment tools & 93 & $\ldots$ & $\ldots$ & 93 \\
\hline Launch and control & 60 & $\ldots$ & $\ldots$ & 60 \\
\hline$\wedge$ Human response to threats & $\ldots$ & $\ldots$ & $\ldots$ & $\ldots$ \\
\hline Counter CBRNE threats & $\ldots$ & $\ldots$ & $\ldots$ & $\ldots$ \\
\hline
\end{tabular}

*More than 100 instances

$>$ Less than 10 instances in lead

$\wedge$ Less than 5 instances in collaborate 


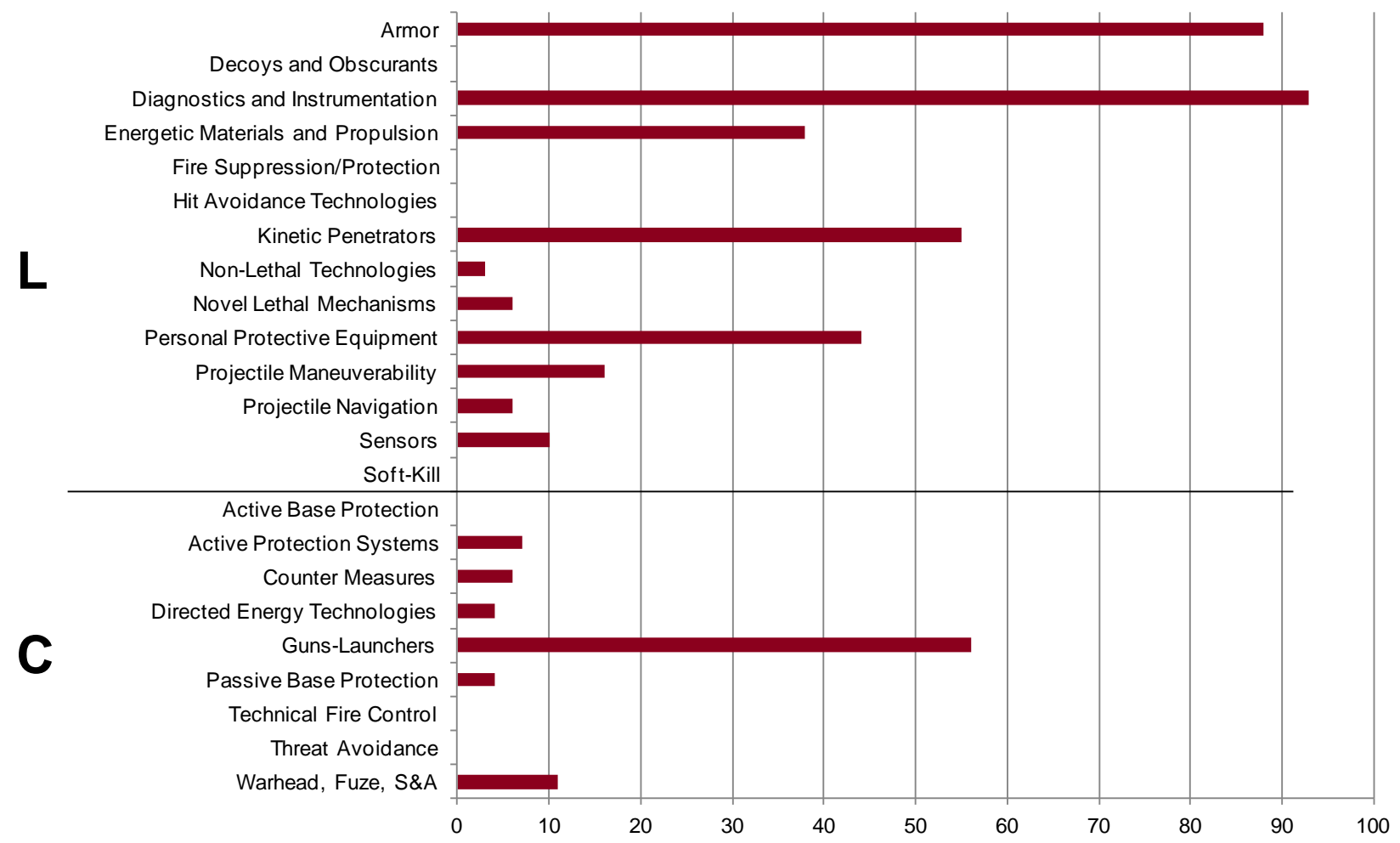

Fig. E-4 Instances chosen for Sciences for Lethality and Protection Campaign competencies for proficiency level 3 only (competency list created for data collection) 
Fig. E-5 Personnel choosing Sciences for Lethality and Protection Campaign competencies for proficiency level 3 only (competency list created for data collection)

\begin{tabular}{|l|c|c|c|c|}
\hline \multicolumn{1}{|c|}{ Sciences for Lethality and Protection } & Civilians & Post Docs & Contractors & Total \\
\hline Armor & 86 & $\ldots$ & 2 & 88 \\
\hline$>$ Decoys and obscurants & 0 & $\ldots$ & $\ldots$ & 0 \\
\hline Diagnostics and instrumentation & 64 & $\ldots$ & 29 & 93 \\
\hline Energetic materials and propulsion & 36 & $\ldots$ & 2 & 38 \\
\hline$>$ Fire suppression/protection & 0 & $\ldots$ & $\ldots$ & 0 \\
\hline$>$ Hit avoidance technologies & 0 & $\ldots$ & $\ldots$ & 0 \\
\hline Kinetic penetrators & 45 & $\ldots$ & 10 & 55 \\
\hline$>$ Non-lethal technologies & 3 & $\ldots$ & $\ldots$ & 3 \\
\hline Novel lethal mechanisms & 6 & $\ldots$ & $\ldots$ & 6 \\
\hline Personal protective equipment & 38 & $\ldots$ & 6 & 44 \\
\hline Projectile maneuverability & 14 & $\ldots$ & 2 & 16 \\
\hline$>$ Projectile navigation & 6 & $\ldots$ & $\ldots$ & 6 \\
\hline Sensors & 10 & $\ldots$ & $\ldots$ & 10 \\
\hline$>$ Soft-kill & 0 & $\ldots$ & $\ldots$ & 0 \\
\hline$\wedge$ Active base protection & 0 & $\ldots$ & $\ldots$ & 0 \\
\hline Active protection systems & 6 & $\ldots$ & 1 & 7 \\
\hline Counter measures & 6 & $\ldots$ & $\ldots$ & 6 \\
\hline Directed energy technologies & 4 & $\ldots$ & $\ldots$ & 4 \\
\hline Guns-Launchers & 45 & $\ldots$ & 11 & 56 \\
\hline Passive base protection & 4 & $\ldots$ & $\ldots$ & 4 \\
\hline$\wedge$ Technical fire control & 0 & $\ldots$ & $\ldots$ & 0 \\
\hline$\wedge$ Threat avoidance & 11 & $\ldots$ & $\ldots$ & 0 \\
\hline Warhead, fuze, S and A & & & $\ldots$ & 11 \\
\hline$>$ Les & 0 & & \\
\hline
\end{tabular}

$>$ Less than 10 instances in lead

$\wedge$ Less than 5 instances in collaborate 
INTENTIONALLY LEFT BLANK. 


\section{Appendix F. Sciences for Maneuver Campaign Data}




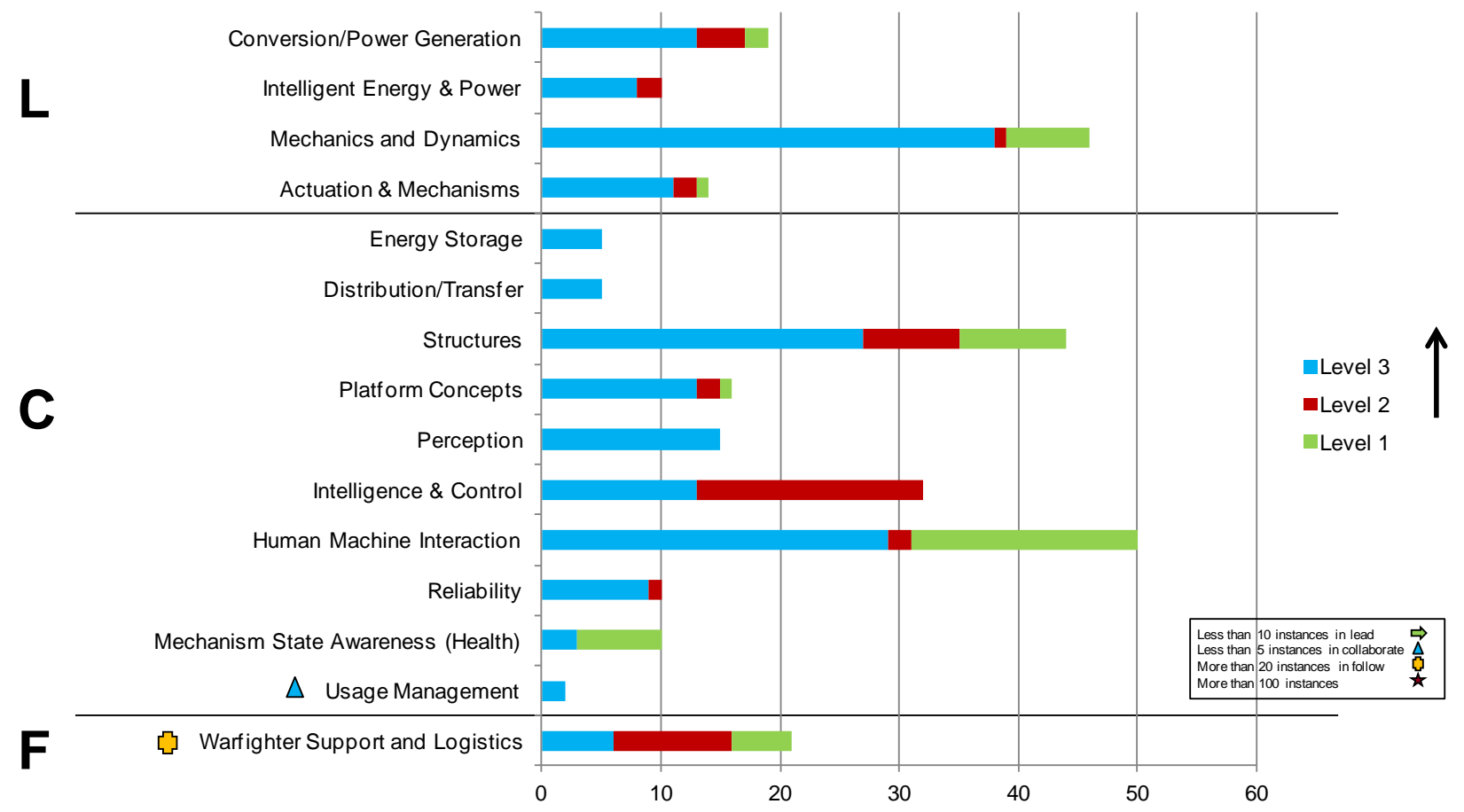

Fig. F-1 Instances chosen for Sciences for Maneuver Campaign competencies

Table F-1 Personnel choosing Sciences for Maneuver Campaign competencies

\begin{tabular}{|l|c|c|c|c|}
\hline \multicolumn{1}{|c|}{ Sciences for Maneuver } & Civilians & Post Docs & Contractors & Total \\
\hline Conversion/power generation & 19 & $\ldots$ & $\ldots$ & 19 \\
\hline Intelligent energy and power & 10 & $\ldots$ & $\ldots$ & 10 \\
\hline Mechanics and dynamics & 41 & $\ldots$ & 5 & 46 \\
\hline Actuation and mechanisms & 11 & $\ldots$ & 3 & 14 \\
\hline Energy storage & 5 & $\ldots$ & $\ldots$ & 5 \\
\hline Distribution/transfer & 5 & $\ldots$ & $\ldots$ & 5 \\
\hline Structures & 41 & 1 & 2 & 44 \\
\hline Platform concepts & 16 & $\ldots$ & $\ldots$ & 16 \\
\hline Perception & 14 & 1 & $\ldots$ & 15 \\
\hline Intelligence and control & 28 & 1 & 3 & 32 \\
\hline Human machine interaction & 39 & $\ldots$ & 11 & 50 \\
\hline Reliability & 10 & $\ldots$ & $\ldots$ & 10 \\
\hline Mechanism state awareness (Health) & 10 & $\ldots$ & $\ldots$ & 10 \\
\hline$\wedge$ Usage management & 2 & $\ldots$ & $\ldots$ & 2 \\
\hline+ Warfighter support and logistics & 15 & $\ldots$ & 6 & 21 \\
\hline
\end{tabular}

$\wedge$ Less than 5 instances in collaborate

+More than 20 instances in follow 


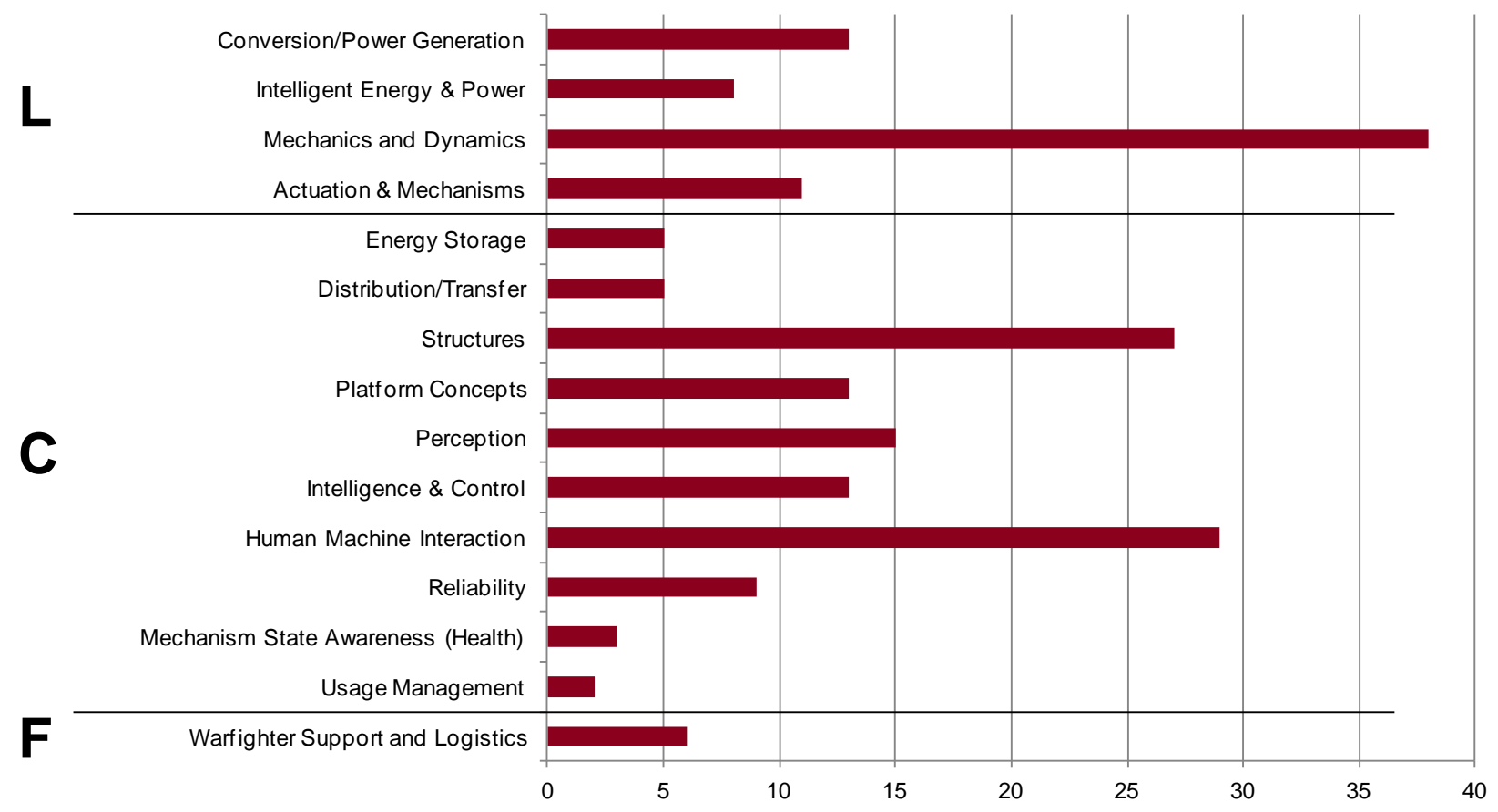

Fig. F-2 Instances chosen for Sciences for Maneuver Campaign competencies for proficiency level 3 only 
Table F-2 Personnel choosing Sciences for Maneuver Campaign competencies for proficiency level 3 only

\begin{tabular}{|c|c|c|c|c|}
\hline Sciences for Maneuver & Civilians & Post Docs & Contractors & Total \\
\hline Conversion/power generation & 13 & $\ldots$ & $\ldots$ & 13 \\
\hline Intelligent energy and power & 8 & $\ldots$ & $\ldots$ & 8 \\
\hline Mechanics and dynamics & 34 & $\ldots$ & 4 & 38 \\
\hline Actuation and mechanisms & 10 & $\ldots$ & 1 & 11 \\
\hline Energy storage & 5 & $\ldots$ & $\ldots$ & 5 \\
\hline Distribution/transfer & 5 & $\ldots$ & $\ldots$ & 5 \\
\hline Structures & 25 & 1 & 1 & 27 \\
\hline Platform concepts & 13 & $\ldots$ & $\ldots$ & 13 \\
\hline Perception & 14 & 1 & $\ldots$ & 15 \\
\hline Intelligence and control & 11 & $\ldots$ & 2 & 13 \\
\hline Human machine interaction & 20 & $\ldots$ & 9 & 29 \\
\hline Reliability & 9 & $\ldots$ & $\ldots$ & 9 \\
\hline Mechanism state awareness (Health) & 3 & $\ldots$ & $\ldots$ & 3 \\
\hline$\wedge$ Usage management & 2 & $\ldots$ & $\ldots$ & 2 \\
\hline +Warfighter support and logistics & 6 & $\ldots$ & $\ldots$ & 6 \\
\hline
\end{tabular}

$\wedge$ Less than 5 instances in collaborate

+More than 20 instances in follow 


\section{Appendix G. Materials Research Campaign Data}




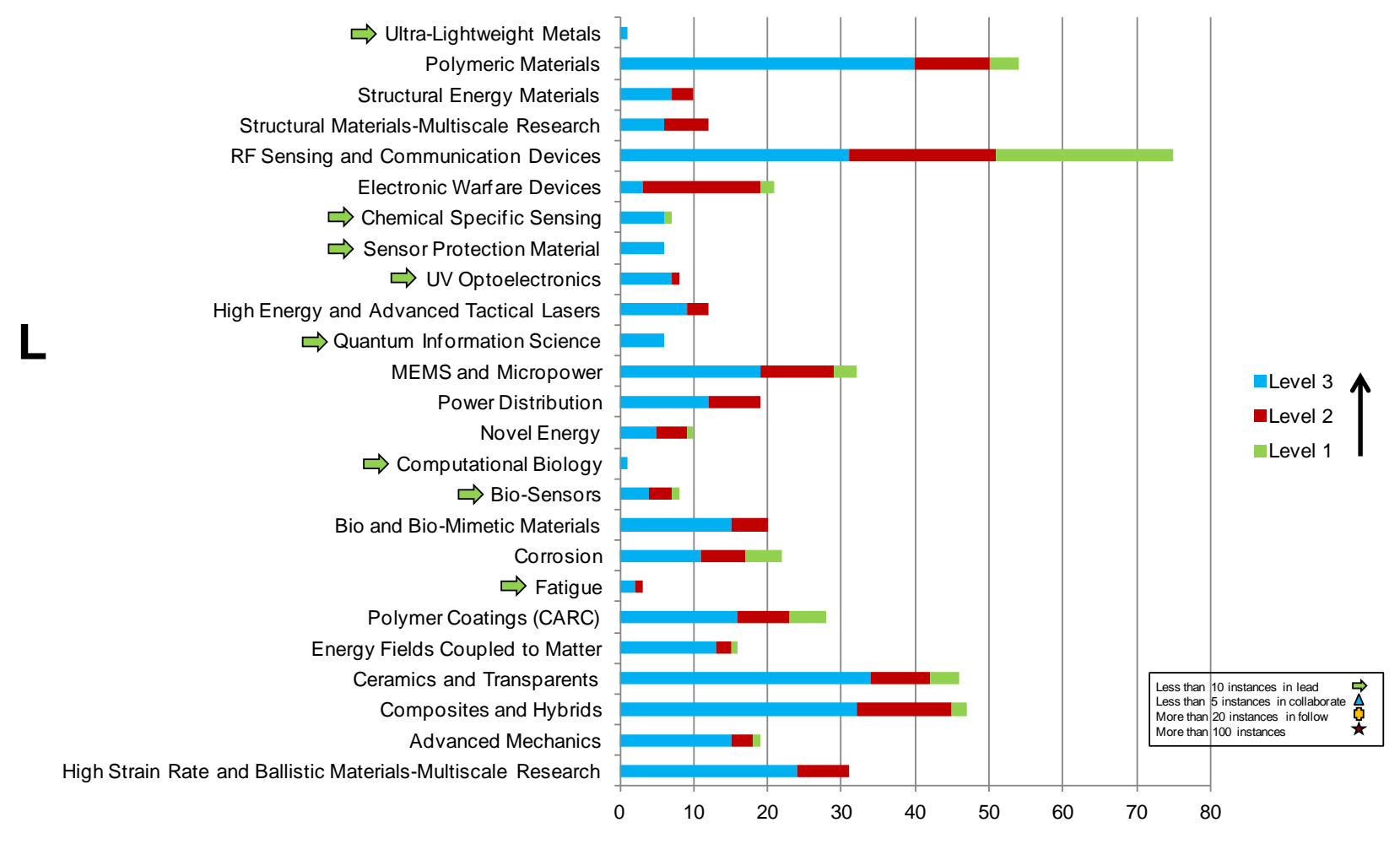

Fig. G-1 Instances chosen for Materials Research Campaign competencies for areas ARL will lead 
Table G-1 Personnel choosing Materials Research Campaign competencies for areas ARL will lead

\begin{tabular}{|l|c|c|c|c|}
\hline \multicolumn{1}{|c|}{ Materials Research } & Civilians & Post Docs & Contractors & Total \\
\hline$>$ Ultra-lightweight metals & 1 & $\ldots$ & $\ldots$ & 1 \\
\hline Polymeric materials & 33 & 9 & 12 & 54 \\
\hline Structural energy materials & 8 & $\ldots$ & 2 & 10 \\
\hline Structural materials-multiscale research & 7 & 1 & 4 & 12 \\
\hline RF sensing and communication devices & 75 & $\ldots$ & $\ldots$ & 75 \\
\hline Electronic warfare devices & 21 & $\ldots$ & $\ldots$ & 21 \\
\hline$>$ Chemical specific sensing & 7 & $\ldots$ & $\ldots$ & 7 \\
\hline$>$ Sensor protection material & 6 & $\ldots$ & $\ldots$ & 6 \\
\hline$>$ UV optoelectronics & 7 & $\ldots$ & 1 & 8 \\
\hline High energy and advanced tactical lasers & 12 & $\ldots$ & $\ldots$ & 12 \\
\hline$>$ Quantum information science & 5 & $\ldots$ & 1 & 6 \\
\hline MEMS and micropower & 28 & $\ldots$ & 4 & 32 \\
\hline Power distribution & 19 & $\ldots$ & $\ldots$ & 19 \\
\hline Novel energy & 10 & $\ldots$ & $\ldots$ & 10 \\
\hline$>$ Computational biology & 1 & $\ldots$ & $\ldots$ & 1 \\
\hline Synthetic biology & 9 & 1 & 2 & 12 \\
\hline$>$ Bio-sensors & 7 & $\ldots$ & 1 & 8 \\
\hline Bio and bio-mimetic materials & 15 & 1 & 4 & 20 \\
\hline Corrosion & 11 & 2 & 9 & 22 \\
\hline$>$ Fatigue & 3 & $\ldots$ & $\ldots$ & 3 \\
\hline Polymer coatings (CARC) & 15 & 3 & 10 & 28 \\
\hline Energy fields coupled to matter & 10 & 3 & 3 & 16 \\
\hline Ceramics and transparents & 28 & 5 & 13 & 46 \\
\hline Composites and hybrids & 28 & 3 & 16 & 47 \\
\hline Advanced mechanics & 13 & 3 & 3 & 19 \\
\hline High strain rate and ballistic materials-multiscale research & 24 & 2 & 5 & 31 \\
\hline$>$
\end{tabular}

$>$ Less than 10 instances in lead 


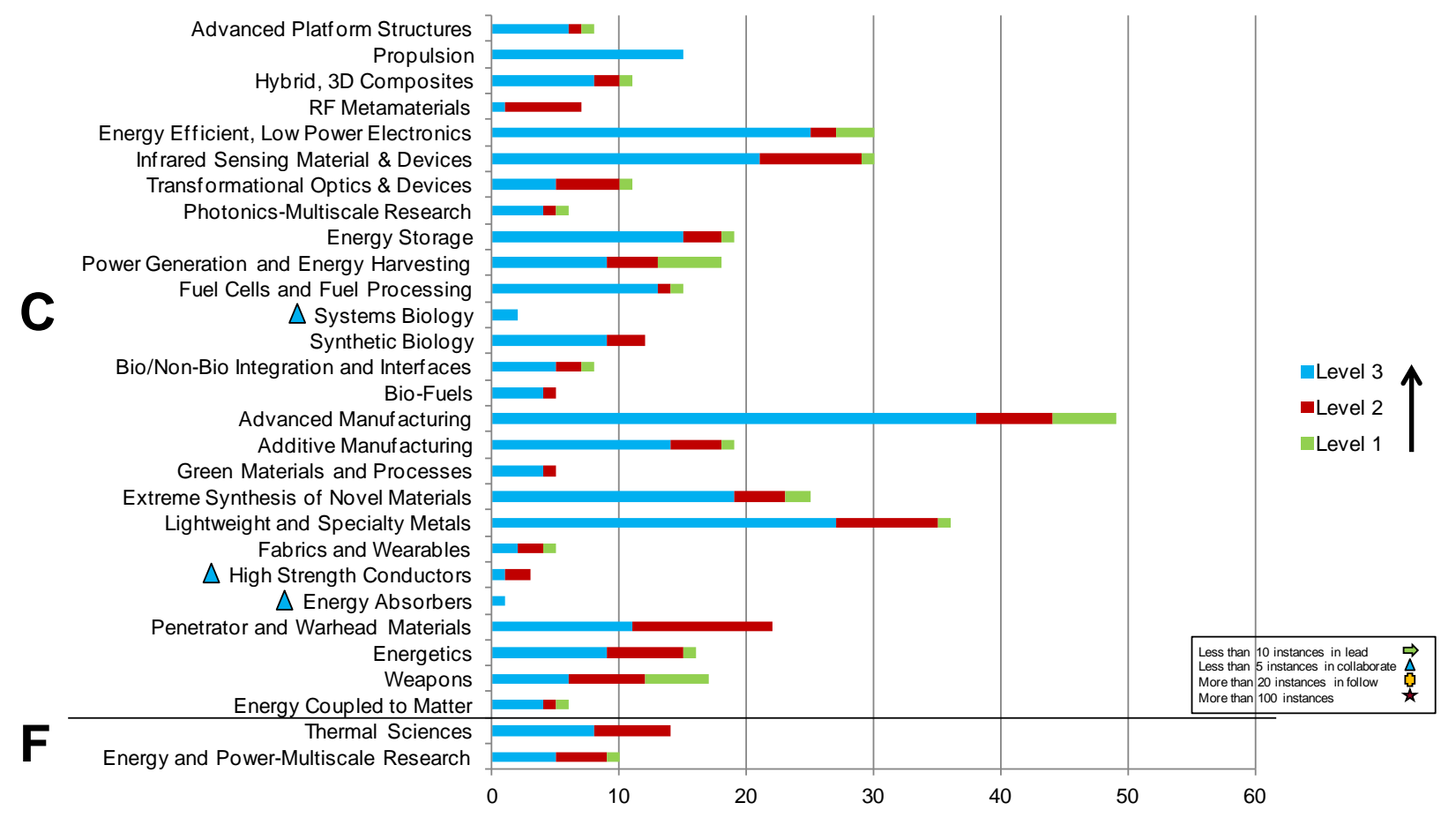

Fig. G-2 Instances chosen for Materials Research Campaign competencies in areas where ARL will collaborate and follow 
Table G-2 Personnel choosing Materials Research Campaign competencies in areas where ARL will collaborate and follow

\begin{tabular}{|c|c|c|c|c|}
\hline $\begin{array}{r}\text { Materials Research } \\
\end{array}$ & Civilians & Post Docs & Contractors & Total \\
\hline Advanced platform structures & 7 & $\ldots$ & 1 & 8 \\
\hline Propulsion & 12 & 1 & 2 & 15 \\
\hline Hybrid, 3D composites & 10 & 1 & $\ldots$ & 11 \\
\hline RF metamaterials & 7 & $\ldots$ & $\ldots$ & 7 \\
\hline Energy efficient, low power electronics & 30 & $\ldots$ & $\ldots$ & 30 \\
\hline Infrared sensing material and devices & 30 & $\ldots$ & $\ldots$ & 30 \\
\hline Transformational optics and devices & 10 & $\ldots$ & 1 & 11 \\
\hline Photonics-multiscale research & 4 & $\ldots$ & 2 & 6 \\
\hline Energy storage & 18 & 1 & $\ldots$ & 19 \\
\hline Power generation and energy harvesting & 18 & $\ldots$ & $\ldots$ & 18 \\
\hline Fuel cells and fuel processing & 12 & 3 & $\ldots$ & 15 \\
\hline$\wedge$ Systems biology & 2 & $\ldots$ & $\ldots$ & 2 \\
\hline Synthetic biology & 9 & 1 & 2 & 12 \\
\hline Bio/non-bio integration and interfaces & 8 & $\ldots$ & $\ldots$ & 8 \\
\hline Bio-fuels & 5 & $\ldots$ & $\ldots$ & 5 \\
\hline Advanced manufacturing & 41 & 2 & 6 & 49 \\
\hline Additive manufacturing & 11 & 1 & 7 & 19 \\
\hline Green materials and processes & 5 & $\ldots$ & $\ldots$ & 5 \\
\hline Extreme synthesis of novel materials & 16 & 4 & 5 & 25 \\
\hline Lightweight and specialty metals & 23 & 2 & 11 & 36 \\
\hline Fabrics and wearables & 4 & $\ldots$ & 1 & 5 \\
\hline$\wedge$ High strength conductors & 3 & $\ldots$ & $\ldots$ & 3 \\
\hline$\wedge$ Energy absorbers & 1 & $\ldots$ & $\ldots$ & 1 \\
\hline Penetrator and warhead materials & 18 & 1 & 3 & 22 \\
\hline Energetics & 15 & $\ldots$ & 1 & 16 \\
\hline Weapons & 11 & $\ldots$ & 6 & 17 \\
\hline Energy coupled to matter & 4 & 1 & 1 & 6 \\
\hline Thermal sciences & 13 & 1 & $\ldots$ & 14 \\
\hline Energy and power-multiscale research & 9 & $\ldots$ & 1 & 10 \\
\hline
\end{tabular}

$\wedge$ Less than 5 instances in collaborate 
Table G-3 Write-in competencies assigned to the Materials Research Campaign

\begin{tabular}{|c|c|}
\hline Competency & Total \\
\hline Antennas & 4 \\
\hline Electronic warfare & 9 \\
\hline Embedded systems & 1 \\
\hline Empirical RF device modeling & 1 \\
\hline IC design & 1 \\
\hline MMIC design & 1 \\
\hline mMW sensors & 3 \\
\hline Photographic technologies & 1 \\
\hline RF device linearization & 1 \\
\hline RF devices & 2 \\
\hline RF electronics & 3 \\
\hline Sensitive RF technology & 3 \\
\hline Semiconductor device technology development & 1 \\
\hline Thermal design for electronics & 1 \\
\hline 2D electronic materials & 4 \\
\hline 3D fusion and viewing & 1 \\
\hline Field effects on energy conversion & 1 \\
\hline Materials_-ultra-energetic materials, nuclear reactions and radiation detection & 1 \\
\hline Materials_-ultra-energetic materials and radiation detection & 1 \\
\hline Materials_-wide band gap Electronic devices reliability & 1 \\
\hline MEMS sensors for position, navigation, and timing & 2 \\
\hline Micro and nano devices & 1 \\
\hline Piezoelectric MEMS & 6 \\
\hline Radar and RF phenomenology & 1 \\
\hline Radar hardware design and development & 2 \\
\hline Radar hardware development and testing & 1 \\
\hline Radar signal processing & 4 \\
\hline Radar signature modeling & 4 \\
\hline RF circuit board design and layout & 1 \\
\hline Semiconductor materials and devices & 13 \\
\hline Microbiology & 1 \\
\hline Adhesives and interfaces & 1 \\
\hline Atomic physics & 1 \\
\hline Detonation physics, shock physics, detonation science & 1 \\
\hline Detonation science & 2 \\
\hline Disruptive energetics & 1 \\
\hline Electromagnetics & 1 \\
\hline Energetic material synthesis & 2 \\
\hline Environmental weathering & 1 \\
\hline Explosives analysis and formulation & 2 \\
\hline Explosives dynamics experimentation & 3 \\
\hline Explosives formulation & 1 \\
\hline Explosives formulation and processing & 1 \\
\hline
\end{tabular}


Table G-3...Write-in competencies assigned to the Materials Research Campaign (continued)

\begin{tabular}{|l|c|}
\hline \multicolumn{1}{|c|}{ Competency } & Total \\
\hline Explosives processing & 2 \\
\hline Insensitive explosives and munitions & 1 \\
\hline Materials sciences—-non-destructive inspection & 3 \\
\hline Materials sciences—-supersonic particle deposition - cold spray & 1 \\
\hline Materials sciences—materials databases and informatics & 1 \\
\hline Materials specifications and standards & 2 \\
\hline Polymer physics & 1 \\
\hline Polymer processing & 1 \\
\hline Quantum and atomistic modeling of materials & 1 \\
\hline Transport through polymers & 1 \\
\hline Energy absorbers & 2 \\
\hline Computational material modeling & 1 \\
\hline Powder metallurgy & 1 \\
\hline Tribology & 1 \\
\hline Non-destructive inspection & 1 \\
\hline Advanced semiconductor metrology & 1 \\
\hline Analog, mixed signal, and RFIC design & 1 \\
\hline Sensitive RF measurements and testing & 1 \\
\hline
\end{tabular}




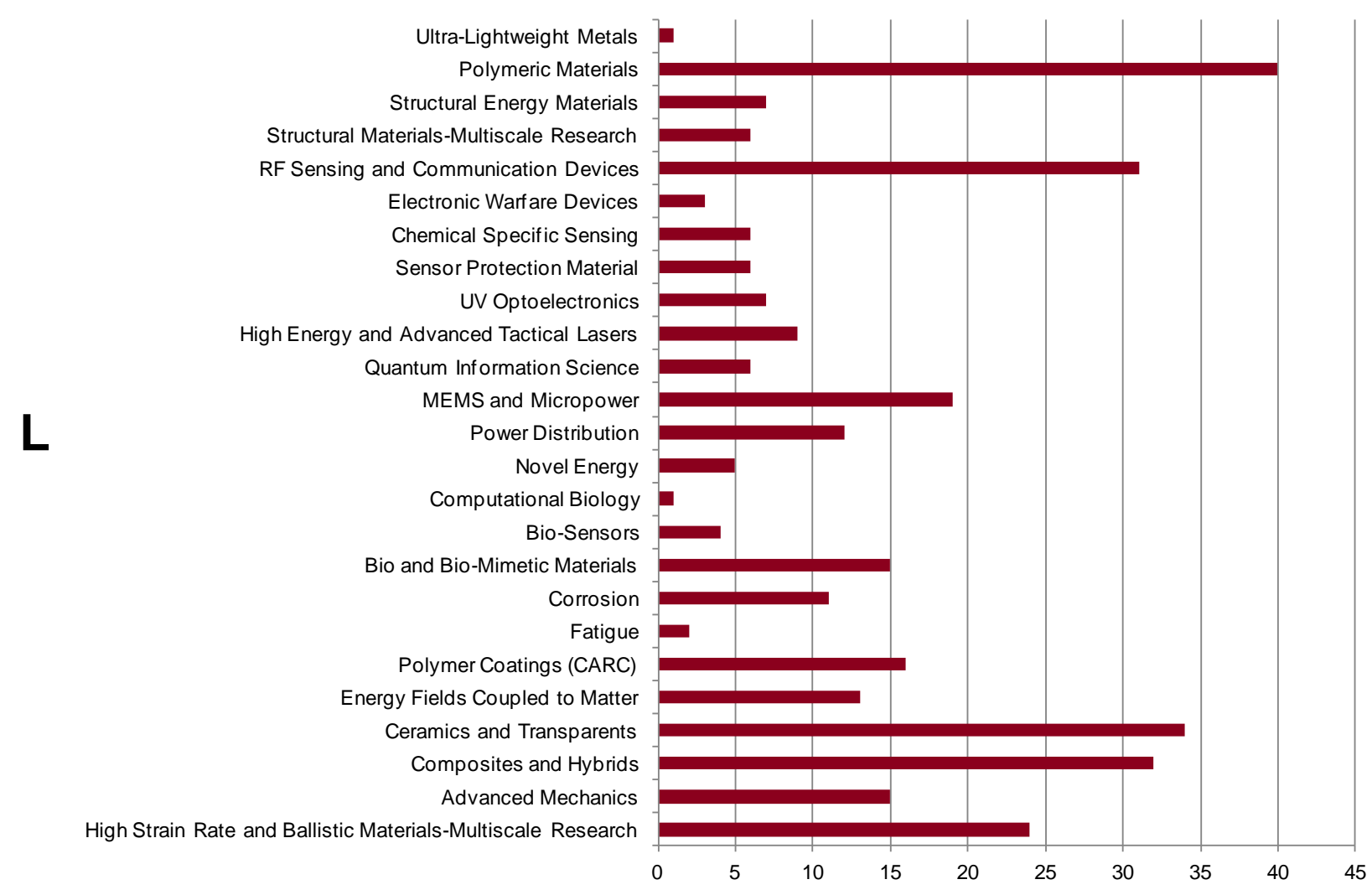

Fig. G-3 Instances chosen for Materials Research Campaign competencies for proficiency level 3 only in areas where ARL will lead 
Table G-4 Personnel choosing Materials Research Campaign competencies for proficiency level 3 only in areas where ARL will lead

\begin{tabular}{|l|c|c|c|c|}
\hline \multicolumn{1}{|c|}{ Materials Research } & Civilians & Post Docs & Contractors & Total \\
\hline >Ultra-lightweight metals & 1 & $\ldots$ & $\ldots$ & 1 \\
\hline Polymeric materials & 33 & $\ldots$ & 7 & 40 \\
\hline Structural energy materials & 7 & $\ldots$ & $\ldots$ & 7 \\
\hline Structural materials-multiscale research & 5 & $\ldots$ & 1 & 6 \\
\hline RF sensing and communication devices & 31 & $\ldots$ & $\ldots$ & 31 \\
\hline Electronic warfare devices & 3 & $\ldots$ & $\ldots$ & 3 \\
\hline$>$ Chemical specific sensing & 6 & $\ldots$ & $\ldots$ & 6 \\
\hline >Sensor protection material & 6 & $\ldots$ & $\ldots$ & 6 \\
\hline$>$ UV optoelectronics & 6 & $\ldots$ & 1 & 7 \\
\hline High energy and advanced tactical lasers & 9 & $\ldots$ & $\ldots$ & 9 \\
\hline$>$ Quantum information science & 5 & $\ldots$ & 1 & 6 \\
\hline MEMS and micropower & 18 & $\ldots$ & 1 & 19 \\
\hline Power distribution & 12 & $\ldots$ & $\ldots$ & 12 \\
\hline Novel energy & 5 & $\ldots$ & $\ldots$ & 5 \\
\hline$>$ Computational biology & 1 & $\ldots$ & $\ldots$ & 1 \\
\hline Synthetic biology & 9 & $\ldots$ & $\ldots$ & 9 \\
\hline$>$ Bio-sensors & 3 & $\ldots$ & 1 & 4 \\
\hline Bio and bio-mimetic materials & 12 & $\ldots$ & 3 & 15 \\
\hline Corrosion & 9 & $\ldots$ & 2 & 11 \\
\hline$>$ Fatigue & 2 & $\ldots$ & $\ldots$ & 2 \\
\hline Polymer coatings (CARC) & 14 & $\ldots$ & 2 & 16 \\
\hline Energy fields coupled to matter & 11 & $\ldots$ & 2 & 13 \\
\hline Ceramics and transparents & 27 & $\ldots$ & 7 & 34 \\
\hline Composites and hybrids & 24 & $\ldots$ & 8 & 32 \\
\hline Advanced mechanics & 14 & $\ldots$ & 1 & 15 \\
\hline High strain rate and ballistic materials-multiscale research & 20 & $\ldots$ & 4 & 24 \\
\hline$>$ Less to & & & & \\
\hline
\end{tabular}

$>$ Less than 10 instances in lead 


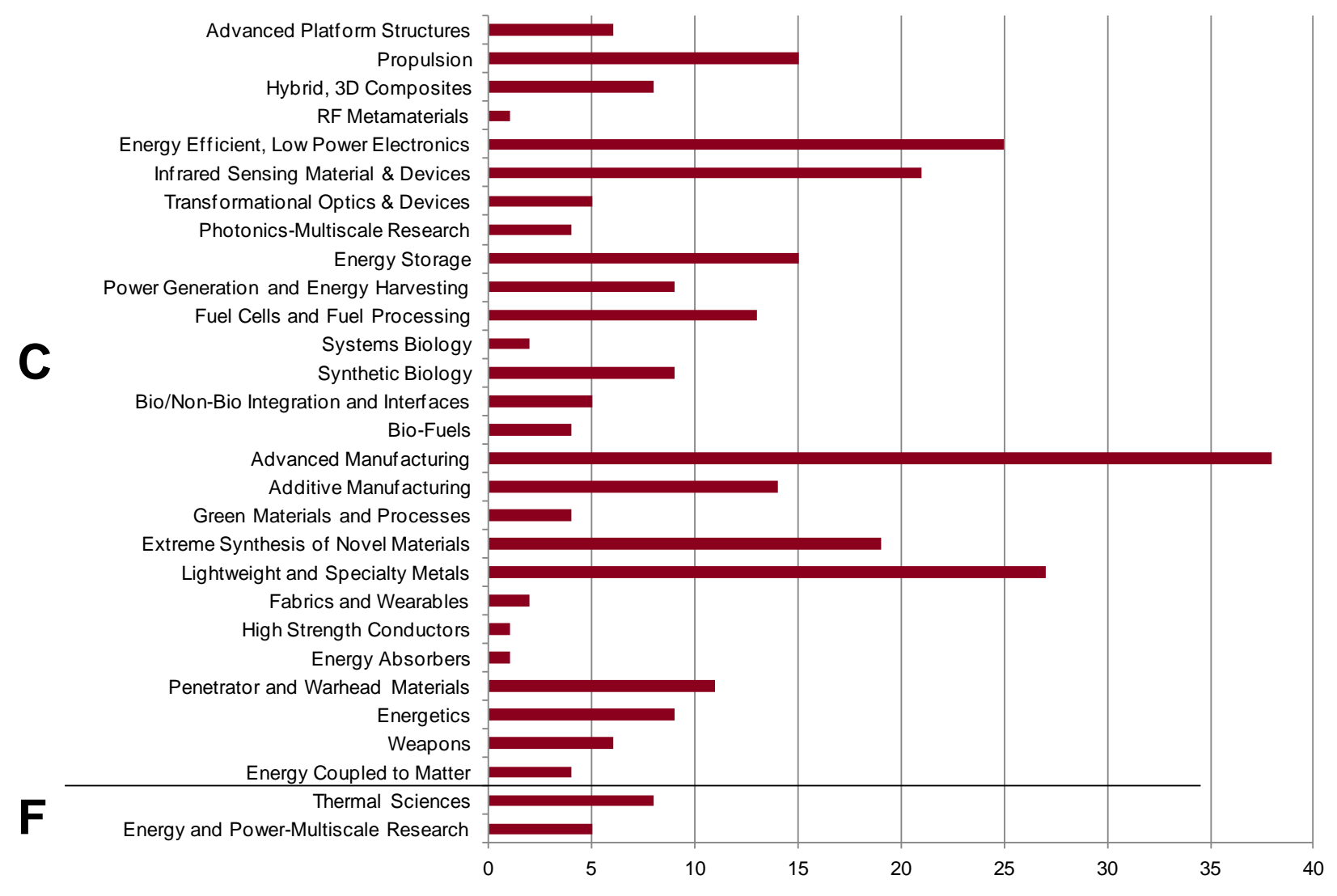

Fig. G-4 Instances chosen for Materials Research Campaign competencies for proficiency level 3 only in areas where ARL will collaboration and follow 
Table G-5 Personnel choosing Materials Research Campaign competencies for proficiency level 3 only in areas where ARL will collaborate and follow

\begin{tabular}{|l|c|c|c|c|}
\hline \multicolumn{1}{|c|}{ Materials Research } & Civilians & Post Docs & Contractors & Total \\
\hline Advanced platform structures & 6 & $\ldots$ & $\ldots$ & 6 \\
\hline Propulsion & 12 & 1 & 2 & 15 \\
\hline Hybrid, 3D composites & 8 & $\ldots$ & $\ldots$ & 8 \\
\hline RF metamaterials & 1 & $\ldots$ & $\ldots$ & 1 \\
\hline Energy efficient, low power electronics & 25 & $\ldots$ & $\ldots$ & 25 \\
\hline Infrared sensing material and devices & 21 & $\ldots$ & $\ldots$ & 21 \\
\hline Transformational optics and devices & 4 & $\ldots$ & 1 & 5 \\
\hline Photonics-multiscale research & 2 & $\ldots$ & 2 & 4 \\
\hline Energy storage & 15 & $\ldots$ & $\ldots$ & 15 \\
\hline Power generation and energy harvesting & 9 & $\ldots$ & $\ldots$ & 9 \\
\hline Fuel cells and fuel processing & 11 & 2 & $\ldots$ & 13 \\
\hline$\wedge$ Systems biology & 2 & $\ldots$ & $\ldots$ & 2 \\
\hline Bio/non-bio integration and interfaces & 5 & $\ldots$ & $\ldots$ & 5 \\
\hline Bio-fuels & 4 & $\ldots$ & $\ldots$ & 4 \\
\hline Advanced manufacturing & 35 & $\ldots$ & 3 & 38 \\
\hline Additive manufacturing & 6 & $\ldots$ & 8 & 14 \\
\hline Green materials and processes & 4 & $\ldots$ & $\ldots$ & 4 \\
\hline Extreme synthesis of novel materials & 15 & $\ldots$ & 4 & 19 \\
\hline Lightweight and specialty metals & 21 & $\ldots$ & 6 & 27 \\
\hline Fabrics and wearables & 2 & $\ldots$ & $\ldots$ & 2 \\
\hline$\wedge$ High strength conductors & 1 & $\ldots$ & $\ldots$ & 1 \\
\hline$\wedge$ Energy absorbers & 1 & $\ldots$ & $\ldots$ & 1 \\
\hline Penetrator and warhead materials & 11 & $\ldots$ & $\ldots$ & 11 \\
\hline Energetics & 8 & $\ldots$ & 1 & 9 \\
\hline Weapons & 3 & $\ldots$ & $\ldots$ & 6 \\
\hline Energy coupled to matter & 7 & 1 & $\ldots$ & 8 \\
\hline Thermal sciences & 4 & $\ldots$ & 1 & 5 \\
\hline Energy and power-multiscale research & $\ldots$ & $\ldots$ & 4 \\
\hline
\end{tabular}

$\wedge$ Less than 5 instances in collaborate 
INTENTIONALLY LEFT BLANK. 


\section{Appendix H. Computational Sciences Campaign Data}

This appendix appears in its original form, without editorial change. 


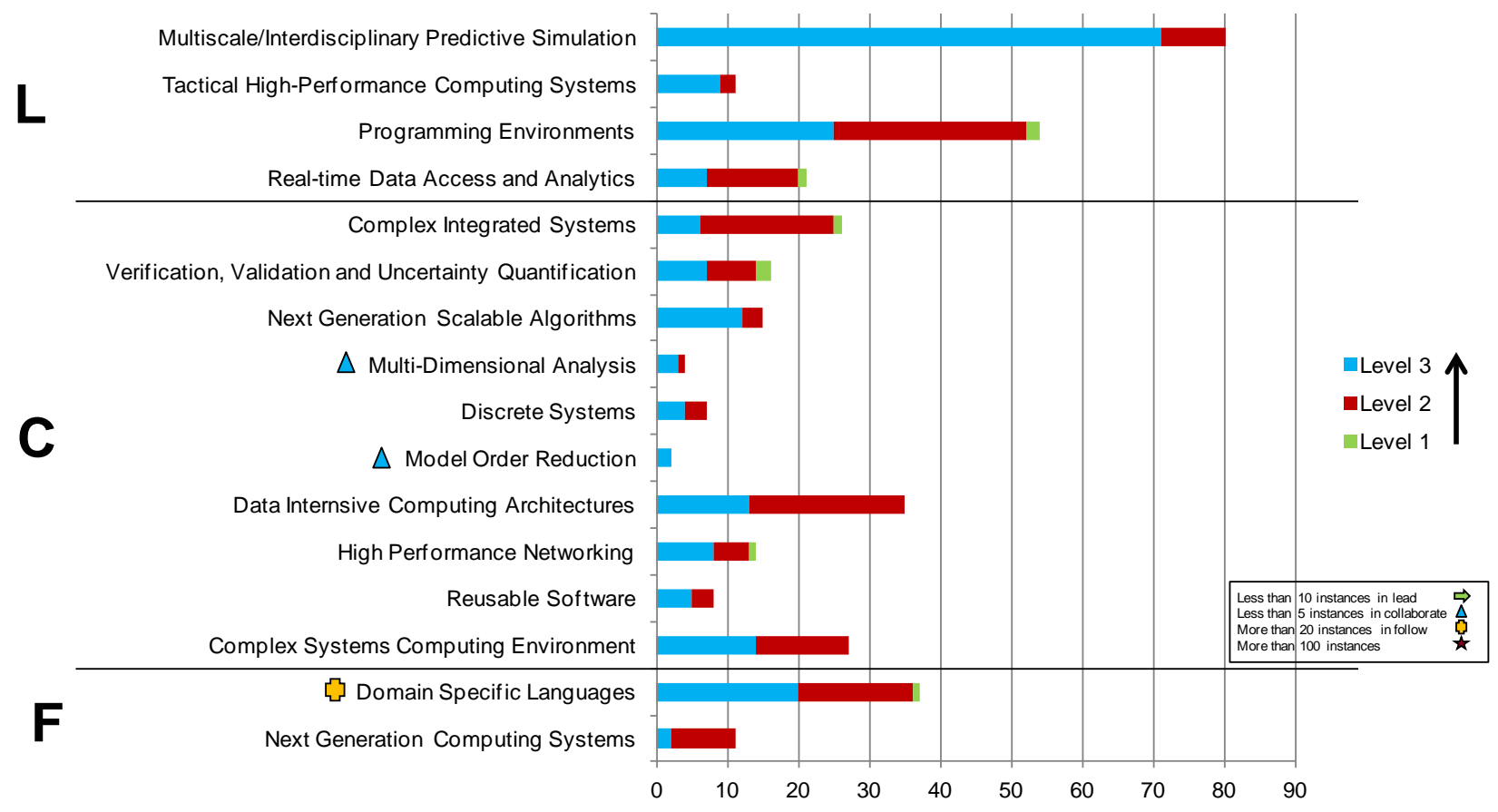

Fig. H-1 Instances chosen for Computational Sciences Campaign competencies

Table H-1 Personnel choosing Computational Sciences Campaign competencies

\begin{tabular}{|l|c|c|c|c|}
\hline \multicolumn{1}{|c|}{ Computational Sciences } & Civilians & Post Docs & Contractors & Total \\
\hline Multiscale/interdisciplinary predictive simulation & 46 & 12 & 22 & 80 \\
\hline Tactical high-performance computing systems & 10 & 1 & $\ldots$ & 11 \\
\hline Programming environments & 34 & $\ldots$ & 20 & 54 \\
\hline Real-time data access and analytics & 18 & $\ldots$ & 3 & 21 \\
\hline Complex integrated systems & 25 & $\ldots$ & 1 & 26 \\
\hline Verification, validation and uncertainty quantification & 16 & $\ldots$ & $\ldots$ & 16 \\
\hline Next generation scalable algorithms & 8 & 2 & 5 & 15 \\
\hline$\wedge$ Multi-dimensional analysis & 4 & $\ldots$ & $\ldots$ & 4 \\
\hline Discrete systems & 3 & 1 & 3 & 7 \\
\hline$\wedge$ Model order reduction & 0 & $\ldots$ & 2 & 2 \\
\hline Data intensive computing architectures & 17 & $\ldots$ & 18 & 35 \\
\hline High performance networking & 9 & $\ldots$ & 5 & 14 \\
\hline Reusable software & 3 & $\ldots$ & 5 & 8 \\
\hline Complex systems computing environment & 14 & $\ldots$ & 13 & 27 \\
\hline +Domain specific languages & 27 & $\ldots$ & 10 & 37 \\
\hline Next generation computing systems & 5 & $\ldots$ & 6 & 11 \\
\hline
\end{tabular}

$\wedge$ Less than 5 instances in collaborate

+More than 20 instances in follow 
Table H-2 Write-in competencies assigned to Computational Sciences Campaign

\begin{tabular}{|l|c|}
\hline \multicolumn{1}{|c|}{ Competency } & Total \\
\hline Multiscale/inter-predictive simulation & 1 \\
\hline Semi-supervised image classification & 1 \\
\hline
\end{tabular}

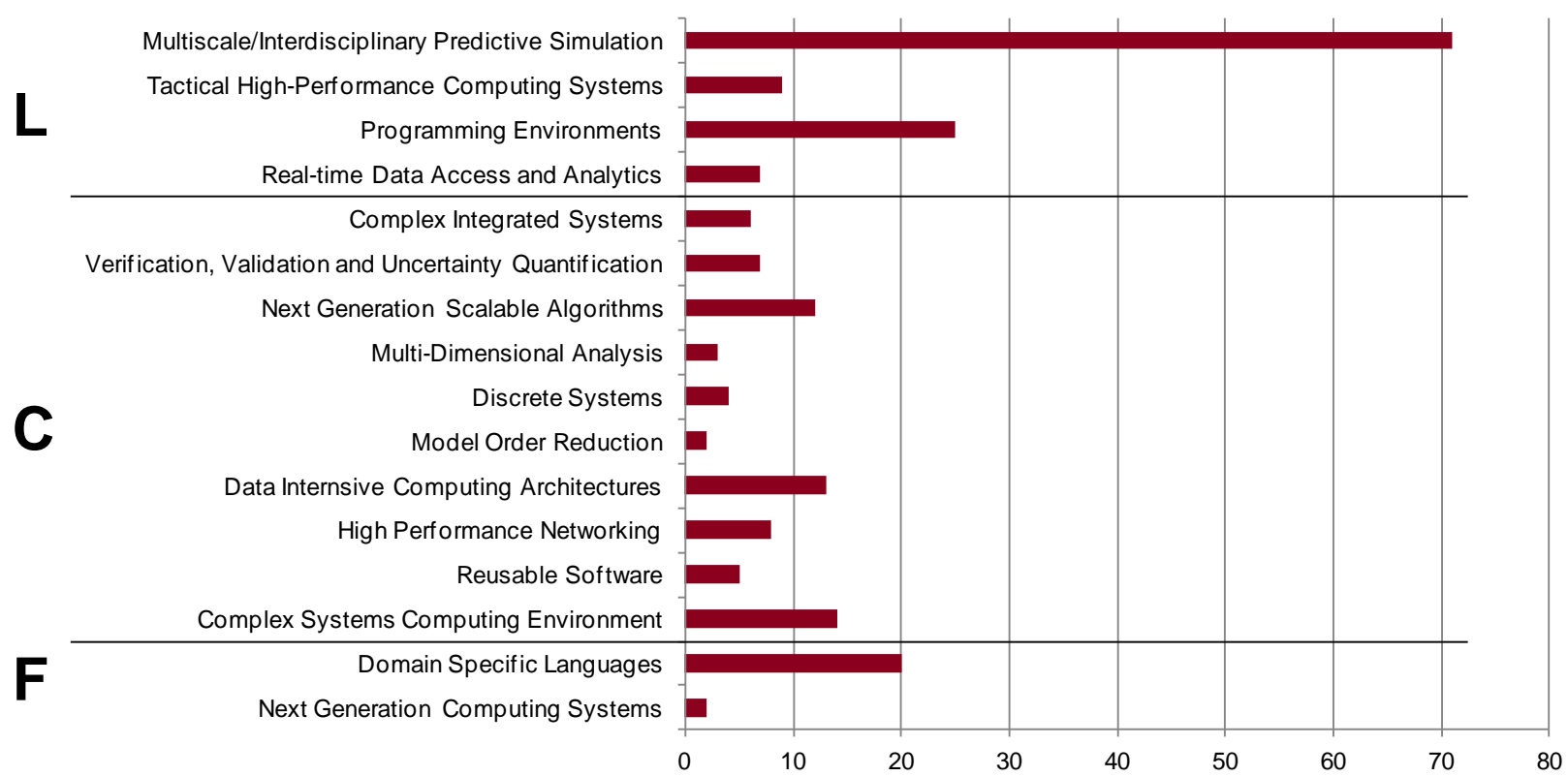

Fig. H-2 Instances chosen for Computational Sciences Campaign competencies for proficiency level 3 only

Table H-3 Personnel choosing Computational Sciences Campaign competencies for proficiency level 3 only

\begin{tabular}{|l|c|c|c|c|}
\hline \multicolumn{1}{|c|}{ Computational Sciences } & Civilians & Post Docs & Contractors & Total \\
\hline Multiscale/interdisciplinary predictive simulation & 54 & 1 & 16 & 71 \\
\hline Tactical high-performance computing systems & 6 & 1 & 2 & 9 \\
\hline Programming environments & 18 & $\ldots$ & 7 & 25 \\
\hline Real-time data access and analytics & 6 & $\ldots$ & 1 & 7 \\
\hline Complex integrated systems & 6 & $\ldots$ & $\ldots$ & 6 \\
\hline Verification, validation and uncertainty quantification & 7 & $\ldots$ & $\ldots$ & 7 \\
\hline Next generation scalable algorithms & 8 & 1 & 3 & 12 \\
\hline$\wedge$ Multi-dimensional analysis & 3 & $\ldots$ & $\ldots$ & 3 \\
\hline Discrete systems & 1 & 1 & 2 & 4 \\
\hline$\wedge$ Model order reduction & 2 & $\ldots$ & $\ldots$ & 2 \\
\hline Data intensive computing architectures & 8 & $\ldots$ & 5 & 13 \\
\hline High performance networking & 5 & $\ldots$ & 3 & 8 \\
\hline Reusable software & 2 & $\ldots$ & 3 & 5 \\
\hline Complex systems computing environment & 10 & $\ldots$ & 4 & 14 \\
\hline+ Domain specific languages & 13 & $\ldots$ & 7 & 20 \\
\hline Next generation computing systems & 1 & $\ldots$ & 1 & 2 \\
\hline
\end{tabular}

$\wedge$ Less than 5 instances in collaborate

+More than 20 instances in follow 
INTENTIONALLY LEFT BLANK. 


\section{Appendix I. Assessment and Analysis Campaign Data}




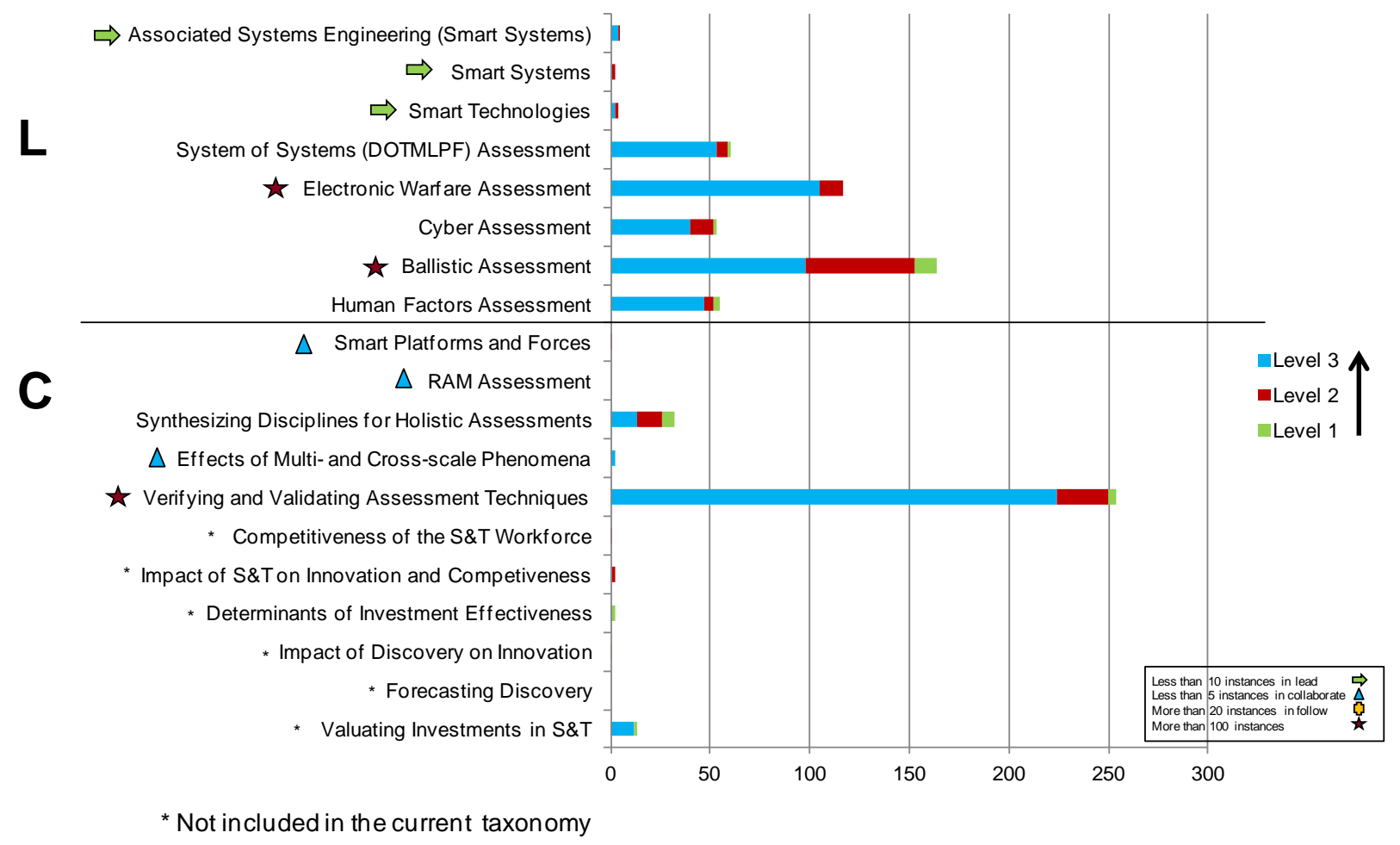

Fig. I-1 Instances chosen for Assessment and Analysis Campaign competencies 
Table I-1 Personnel choosing Assessment and Analysis Campaign competencies

\begin{tabular}{|l|c|c|c|c|}
\hline \multicolumn{1}{|c|}{ Assessment and Analysis } & Civilians & Post Docs & Contractors & Total \\
\hline$>$ Associated systems engineering (smart systems) & 5 & $\ldots$ & $\ldots$ & 5 \\
\hline$>$ Smart systems & 2 & $\ldots$ & $\ldots$ & 2 \\
\hline$>$ Smart technologies & 3 & $\ldots$ & 1 & 4 \\
\hline System of systems (DOTMLPF) assessment & 36 & $\ldots$ & 24 & 60 \\
\hline *Electronic warfare assessment & 76 & $\ldots$ & 41 & 117 \\
\hline Cyber assessment & 44 & $\ldots$ & 9 & 53 \\
\hline *Ballistic assessment & 136 & $\ldots$ & 28 & 164 \\
\hline Human factors assessment & 55 & $\ldots$ & $\ldots$ & 55 \\
\hline$\wedge$ Smart platforms and forces & 1 & $\ldots$ & $\ldots$ & 1 \\
\hline$\wedge$ RAM assessment & 0 & $\ldots$ & $\ldots$ & 0 \\
\hline Synthesizing disciplines for holistic assessments & 24 & $\ldots$ & 8 & 32 \\
\hline$\wedge$ Effects of multi- and cross-scale phenomena & 2 & $\ldots$ & $\ldots$ & 2 \\
\hline *Verifying and validating assessment techniques & 242 & 3 & 9 & 254 \\
\hline \#Competitiveness of the S and T workforce & 1 & $\ldots$ & $\ldots$ & 1 \\
\hline \#Impact of S\&T on innovation and competiveness & 2 & $\ldots$ & $\ldots$ & 2 \\
\hline \#Determinants of Investment effectiveness & 2 & $\ldots$ & $\ldots$ & 2 \\
\hline \#Impact of discovery on innovation & 1 & $\ldots$ & $\ldots$ & 1 \\
\hline \#Forecasting discovery & 0 & $\ldots$ & $\ldots$ & 0 \\
\hline \#Valuating Investments in S and T & 13 & $\ldots$ & $\ldots$ & 13 \\
\hline
\end{tabular}

*More than 100 instances

$>$ Less than 10 instances in lead

$\wedge$ Less than 5 instances in collaborate

\#Not in the current taxonomy

Table I-2 Write-in competencies for Assessment and Analysis Campaign

\begin{tabular}{|l|c|}
\hline \multicolumn{1}{|c|}{ Competency } & Total \\
\hline Assessment and analysis-methodology development & 4 \\
\hline Assessment and analysis, modeling and simulation development & 9 \\
\hline Assessment and analysis, modeling and simulation development, computer-aided geometry techniques & 5 \\
\hline Assessment and analysis, modeling and simulation development, massively parallel techniques & 6 \\
\hline Battlefield injury mechanisms & 1 \\
\hline
\end{tabular}




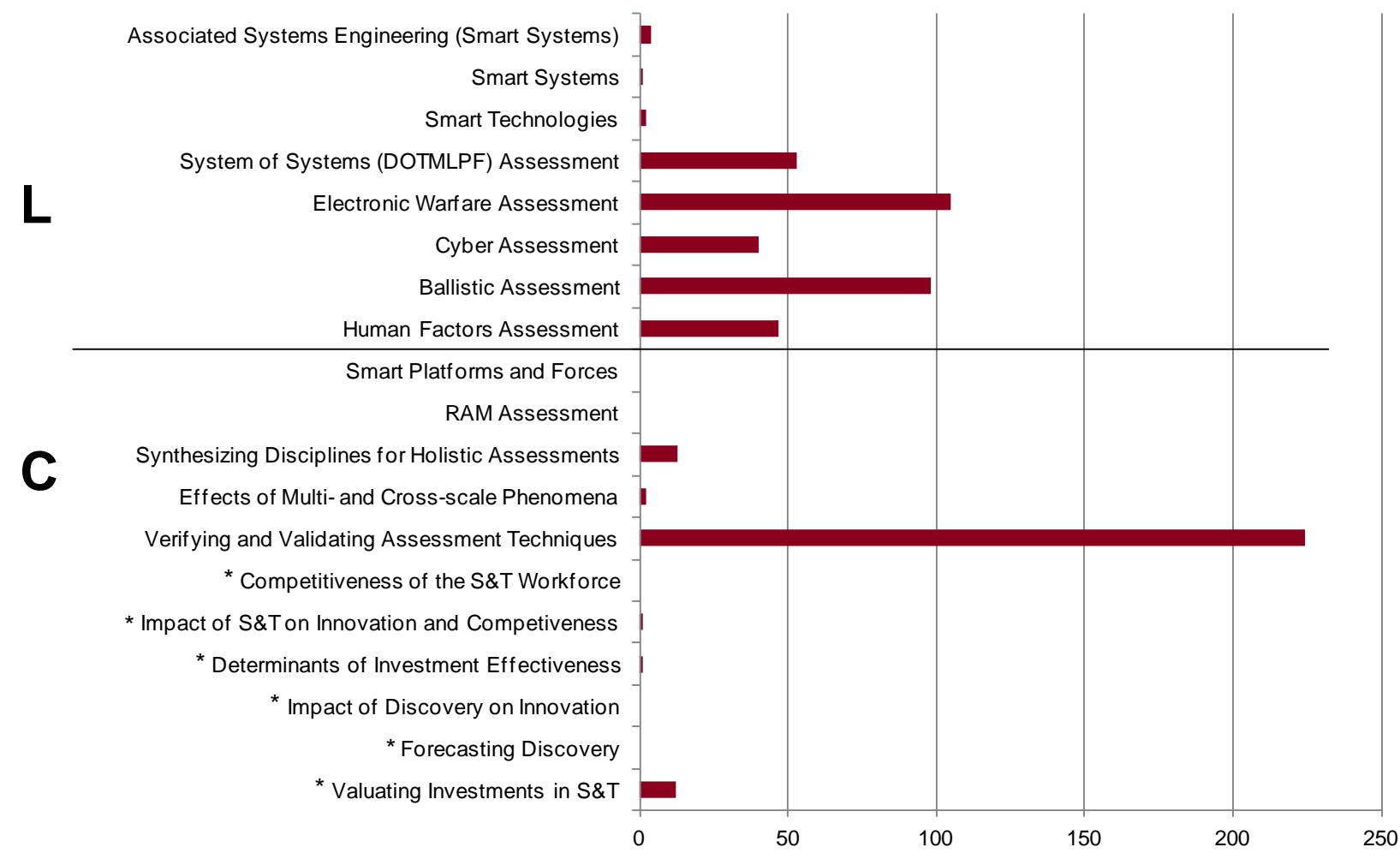

* Not included in the current taxonomy

Fig. I-2 Instances chosen for Assessment and Analysis Campaign competencies for proficiency level 3 only 
Table I-3 Personnel choosing Assessment and Analysis Campaign competencies for proficiency level 3 only

\begin{tabular}{|l|c|c|c|c|}
\hline \multicolumn{1}{|c|}{ Assessment and Analysis } & Civilians & Post Docs & Contractors & Total \\
\hline$>$ Associated systems engineering (smart systems) & 4 & $\ldots$ & $\ldots$ & 4 \\
\hline$>$ Smart systems & 1 & $\ldots$ & $\ldots$ & 1 \\
\hline$>$ Smart technologies & 2 & $\ldots$ & $\ldots$ & 2 \\
\hline System of systems (DOTMLPF) assessment & 30 & $\ldots$ & 23 & 53 \\
\hline *Electronic warfare assessment & 65 & $\ldots$ & 40 & 105 \\
\hline Cyber assessment & 31 & $\ldots$ & 9 & 40 \\
\hline *Ballistic assessment & 84 & $\ldots$ & 14 & 98 \\
\hline Human factors assessment & 47 & $\ldots$ & $\ldots$ & 47 \\
\hline$\wedge$ Smart platforms and forces & 0 & $\ldots$ & $\ldots$ & 0 \\
\hline$\wedge$ RAM assessment & 0 & $\ldots$ & $\ldots$ & 0 \\
\hline Synthesizing disciplines for holistic assessments & 11 & $\ldots$ & 2 & 13 \\
\hline$\wedge$ Effects of multi- and cross-scale phenomena & 2 & $\ldots$ & $\ldots$ & 2 \\
\hline *Verifying and validating assessment techniques & 216 & 2 & 6 & 224 \\
\hline \#Competitiveness of the S and T workforce & 0 & $\ldots$ & $\ldots$ & 0 \\
\hline \#Impact of S and T on innovation and competiveness & 1 & $\ldots$ & $\ldots$ & 1 \\
\hline \#Determinants of investment effectiveness & 1 & $\ldots$ & $\ldots$ & 1 \\
\hline \#Impact of discovery on innovation & 0 & $\ldots$ & $\ldots$ & 0 \\
\hline \#Forecasting discovery & 0 & $\ldots$ & $\ldots$ & 0 \\
\hline \#Valuating investments in S and T & 12 & $\ldots$ & $\ldots$ & 12 \\
\hline
\end{tabular}

$>$ Less than 10 instances in lead

*More than 100 instances

$\wedge$ Less than 5 instances in collaborate

\#NOT in the current taxonomy 
INTENTIONALLY LEFT BLANK. 


\section{List of Symbols, Abbreviations, and Acronyms}

$\begin{array}{ll}\text { ARL } & \text { US Army Research Laboratory } \\ \text { HRED } & \text { Human Research and Engineering Directorate } \\ \text { KSA } & \text { knowledge, skill, and ability } \\ \text { RDECOM } & \text { US Army Research, Development and Engineering Command } \\ \text { S\&E } & \text { Scientist and Engineer } \\ \text { S\&T } & \text { science and technology } \\ \text { SLaP } & \text { Sciences for Lethality and Protection } \\ \text { SWC } & \text { specialty work code } \\ \text { WMRD } & \text { Weapons and Materials Research Directorate }\end{array}$




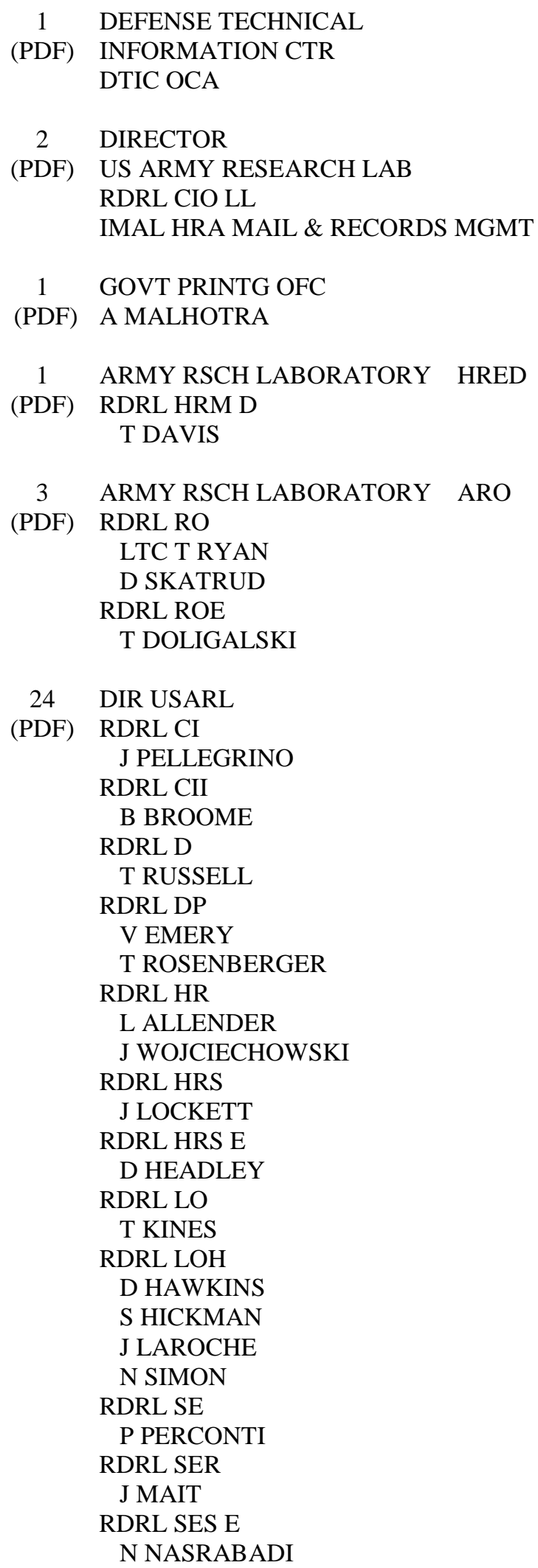

RDRL SL

P TANENBAUM

J BEILFUSS

RDRL VT

M VALCO

S WILKERSON

RDRL VTV

E HABTOUR

RDRL WM

P BAKER

RDRL WML E

$P$ WEINACHT 